\title{
Idade fisiológica, variação sazonal e periodicidade diurna de quatro populaçōes de Tabanidae (Diptera) no Campus Universitário, Manaus, Brasil(*)
}

\author{
J. A. Rafael $(* 0)$ \\ J. D. Chariwood $(\approx *)$
}

\begin{abstract}
Resumo
As quatro populações estudadas, Tabanus dorsiger var. dorsovitattus, T. d. var. modestus, T. importunus e Phaeotabanus cajennensis, apresentaram baixa oniparidade sazonal. A duração do ciclo gonotrófico foi uniforme, atingindo estádio V de Christophers em 120 horas, após um repasto sangüineo completo. A maioria das fêmeas capturadas que chegavam para alimentaçāo tinha o folículo em estádio II. Apenas P. cajennensis năo foi registrada durante todo ano, deixando de ocorrer de dezembro a princípio de fevereiro, no início da estação chuvosa. A atividade de vôo foi maior no período da tarde e diferenças de atividade entre fêmeas nuliparas e oniparas não foram significativas $\left(x^{2}>0,05\right)$.
\end{abstract}

\section{INTRODUÇÃO}

Os Tabanidae, conhecidos popularmente como mutucas, apresentam grande importância, não só como insetos importunos para os animais e o homem, senão também como transmissores de agentes patogênicos como virus, bactérias, protozoas e microfilárias (Barreto, 1949) .

As fêmeas de Tabanidae, sendo quase na totalidade hematófagas, estão envolvidas na transmissão de duas maneiras: funcionando como vetoras mecânicas e em poucos casos como hospedeiros intermediários (transmissão biológica). As transmissões mecânicas (anaplasmose, tularemia) em condições naturais são de maior relevância quando a fêmea obtém seu repasto de maneira intermitente, isto em virtude da dor provocada pela picada (Barreto, 1949). O hospedeiro reage e o inseto procura acabar sua refeição sobre o mesmo ou outro hospedeiro. A importância de um repasto interrompido em relação à transmissão de agentes patogênicos é portanto óbvia e torna-se mais relevante quando se têm informaçōes da idade fisiológica e quando são considerados: a) anautogenia: incapacidade de as fêmeas de insetos desenvolverem um lote de ovos sem ter-se alimentado de fonte proteica (Engelmann, 1970); b) telmofagia: quando o inseto corta a pele do hospedeiro e se alimenta do sangue extravasado (Hocking, 1971); c) grande quantidade de sangue como repasto; os Tabanidae, assim como outros insetos, podem ingerir quantidades de sangue maior que o próprio peso do corpo; d) longo tempo para obter o repasto; e) dor provocada pela picada e f) alimentação interrompida (Krinsky, 1976).

A idade fisiológica é expressa pelo número de ciclos gonotróficos, o qual se inicia pela procura e obtenção de sangue continua com a digestão do sangue e maturação do oócito e se conclui pela oviposição (Detinova, 1962). Uma fêmea que não completou seu primeiro ciclo gonotrófico é denominada nulípara e uma que realizou um ou mais ciclos, onípara. Os termos unípara, bípara, etc. são usados para designar o número de ciclos completados (Bertram, 1962; Forattini, 1962; Thomas, 1972).

Realizamos estudos de determinação da idacie fisiológica de acordo com a variação sazonal e periodicidade diurna para as quatro populações mais abundantes no Campus Universitário: Tabanus dorsiger var. dorsovittatus Macq., T. dorsiger var. modestus Wied., T. importunus Wied., e Phaeotabanus cajennensis (Fab.) para obter informações sobre: biologia

\footnotetext{
(") - Parte da tese apresentada pelo primeiro autor ao Instituto Nacional de Pesquisas da Amazônia (INPA) e Fundação Universidade do Amazonas (FUA) como parte dos requisitos para obtenção do grau de Mestre em Ciências Biológicas.

("*) - Instituto Nacional de Pesquisas da Amazônia, Manaus.
} 
da espécie (Wilkes, 1976), hábitos alimentares, papel do sangue na ovogênese (Magnarelli. 1976), longevidade, idade da classe (Detinova, 1962), período de emergência (Thomas, 1972). viabilidade das fêmeas de Tabanidae como potenciais vetoras de doenças (Troubridge \& Davies, 1975) e índice de sobrevivência.

\section{MATERIAis E MÉTODOS}

As capturas foram realizadas no Campus Universitário da Fundação Universidade do Amazonas (FUA), localizado na periferia de Manaus $\left(03^{\circ} 08^{\prime} 07^{\prime \prime}\right.$ S. $\left.60^{\circ} 00^{\prime} 34^{\prime \prime} W\right)$. Neste local, foram montadas quatro armadilhas de Malaise (Townes, 1962) e uma com isca eqüina. Ambas ficaram na mesma área, distribuídas em terreno alagadiço à beira de um igarapé, orladas por mata primária num dos lados e secundária nos outros. O locai, em que ficaram as armadilhas, apresentava: a) vegetação rasteira com predominância de Gramineae e Cypeceae e ocorrendo menos freqủentemente Piperaceae, Melastomataceae, Rubiaceae, Polipodiaceae e b) arbustos esparsos representados por Guttiferae.

Dados de precipitação, umidade relativa e temperatura foram tomados junto ao serviço de meteorologia do INPA, situado aproximadamente a $1.500 \mathrm{~m}$ do local de coleta. Dados de luminosidade foram locais, realizados com um luximetro Metrawatt de quatro escalas, dando valores de menos de 1 , até $500 \mathrm{mil}$ lux. As leituras $(n=6)$ foram horárias, tomadas com o céu limpo e com a fotocélula acerca de um metro do solo, em local bem aberto. Cada medida foi a média de duas leituras; uma com a fotocélula dirigida ao sol e a outra com a fotocélula dirigida ao céu, perpendicular ao solo.

Semanalmente, durante agosto/78 a agosto $/ 79$, os adultos de Tabanidae capturados nas quatro armadilhas de Malaise foram contados e classificados para acompanhar a variação sazonal.

A armadilha foi construída em estrutura de madeira e tanto na cobertura quanto nos septos inferiores foram pregados, com percevejos, filó poliester Rhodia $\mathrm{R}$ branco (Fig. 1). As dimensões utilizadas são mostradas na Fig. 2.

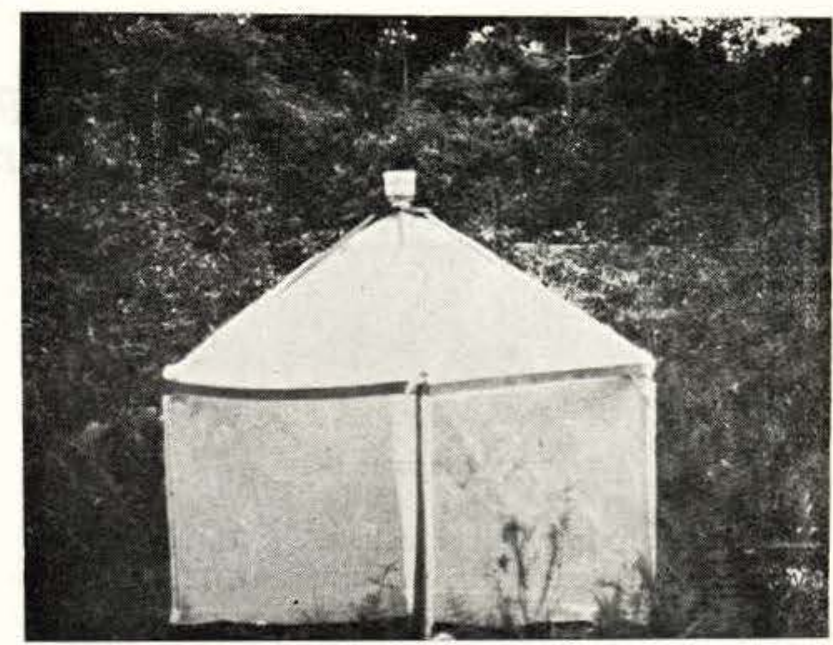

Fig. 1 - Armadilha de Malaise no local de coleta
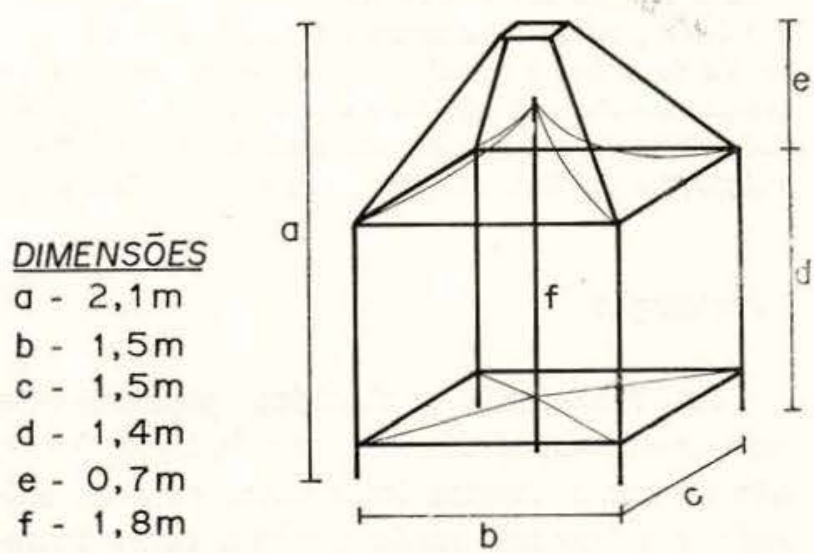

Fig. 2 - Esquema da armadilha de Malaise e suas dimensōes.

O frasco coletor (Fig. 3) consistia em um recipiente transparente e circular de plástico com $12 \mathrm{~cm}$ de altura $\times 13 \mathrm{~cm}$ de diâmetro, com uma placa de petri como tampa para facilitar a tendência fototrópica dos insetos, pois não escurecia o interior do frasco. A entrada para o frasco era através de um funil de copo plástico. adaptado dentro de um tubo de conexão.

O líquido conservador, $100 \mathrm{ml}$ de cloral hidrato $\left(\mathrm{C}_{2} \mathrm{H}_{3} \mathrm{Cl}_{3} \mathrm{O}_{2}\right)$ a $5 \%$, ficava ao redor deste tubo com altura aproximada de $2,0 \mathrm{~cm}$, onde os insetos se iam depositando, sendo semanalmente retirados, transferidos para o álcool $70 \%$ e, em laboratório, os Tabanidae separados, alfinetados e classificados. Os insetos restantes 


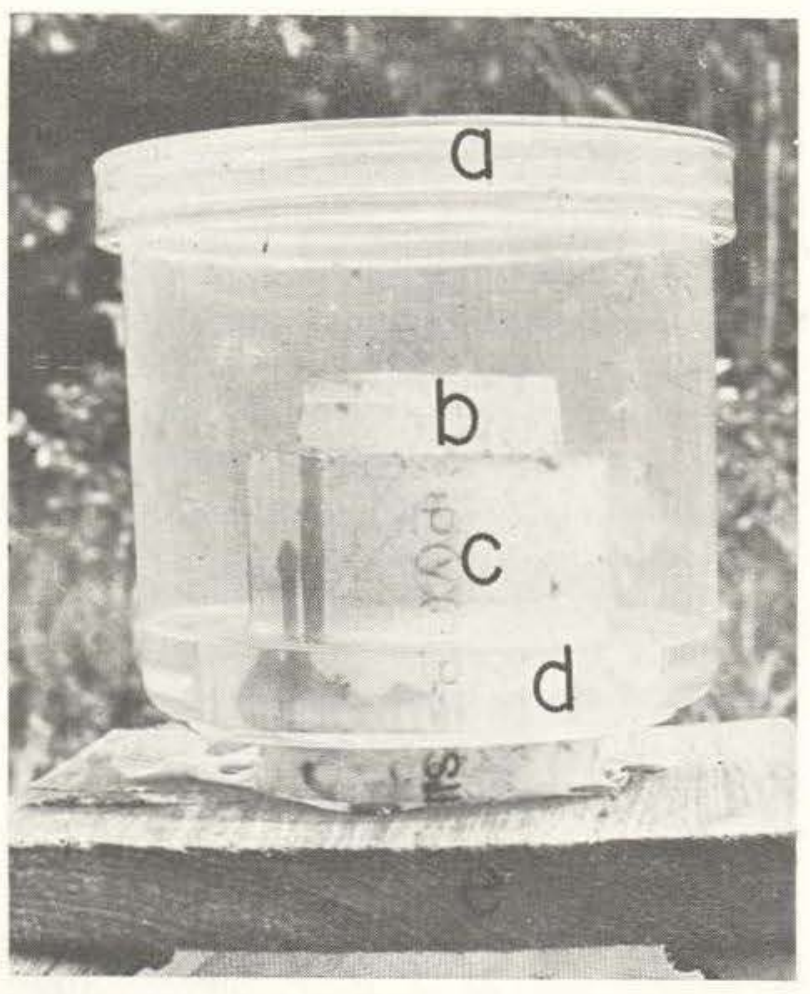

Fig. 3 - Frasco coletor no topo da armadilha de Malaise: $a$ - tampa; b - funil; $c$ - tubo de conexão; $d$ líquido conservador; e - suporte.

continuavam em álcool, devidamente etiquetados para trabalhos posteriores.

Para periodicidade diurna e variação na idade fisiológica, as capturas foram realizadas quinzenalmente, com uma armadilha modificada de Roberts (1977), também em estrutura de madeira, parafusada e coberta com o mesmo tecido utilizado para as armadilhas de Malaise. Este tecido, por ser todo perfurado, permite bom arejamento, tornando-se eficiente na atração de Tabanidae quando um animal é colocado no interior da armadilha. Um esquema e as dimensões utilizadas para armadilha com isca eqüina é mostrada na Fig. 4.

Quando em operação, o filó foi levantado $40 \mathrm{~cm}$ do solo, em todos os lados, para a entrada das mutucas, que ficavam retidas no seu interior e descansavam sobre o tecido ou septos de" madeira, onde eram facilmente coletadas depois de obter, ou năo, sucesso na captura de sangue.
Coletas diárias foram realizadas das 05:30 às 18:00 horas, embora aigumas tenham sido feitas depois das 08:00 horas e terminadas por volta das 17:00 horas. Cada coleta horária foi mantida normalmente em recipientes separados e numerados, sendo, porém utilizados dois ou mais recipientes por hora, quando grande número foi coletado.

Os recipientes que continham as mutucas foram mantidos a $-15^{\circ} \mathrm{C}$ para posterior determinação da idade fisiológica, pelo método de Polovodova (Detinova, 1962) e transcrito na pag. 911 . Em algumas coletas, todas as mutucas foram dissecadas até três meses após a captura. Cuidados foram tomados para que não ocorresse desidratação antes ou durante a armazenagem na câmara frigorífica, mantendo-se os insetos sempre na sombra, em lugar fresco, segundo indicação de Thomas (1972) .

As mutucas capturadas com sangue foram mantidas em gaiolas de tamanhos diferentes, em laboratório, à temperatura de $25-30^{\circ} \mathrm{C}$, e sob a umidade relativa média de $80 \%$, para acompanhar-se o desenvolvimento do folículo e obter-se oviposição. Dissecações seriadas fcram feitas, com essas mutucas, a cada 24 horas, nas mais ativas, sendo estas as que provavelmente tenham desenvolvido o folículo de maneira normal.

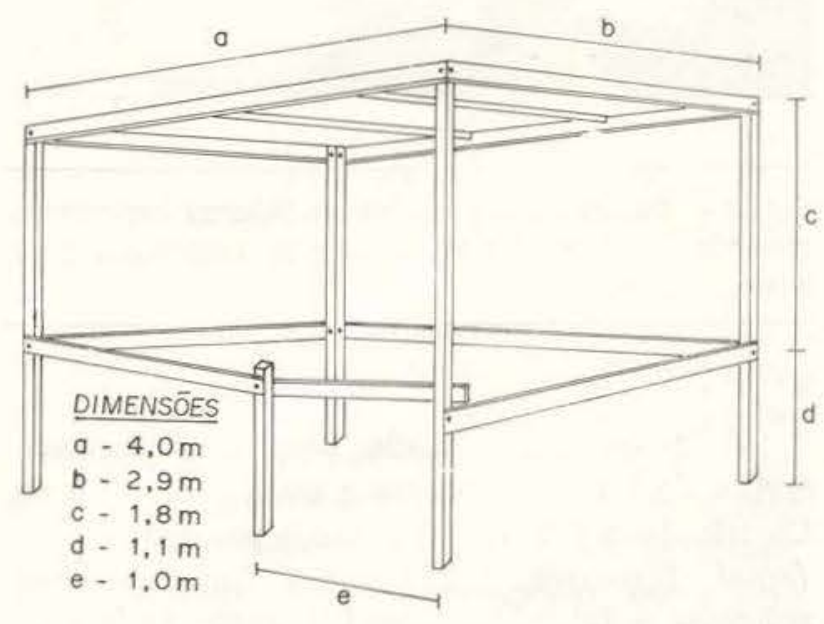

Fig. 4 - Esquema da armadilha para isca eqüina e suas dimensōes. 
Para observar o desenvolvimento do folículo e o número de ciclos gonotróficos, os espécimens foram imobilizados com forte pressão no tórax (quando vivos), colocados sobre sua superfície dorsal na lâmina de microscopia, com um estilete laminado prendendo o tórax do inseto contra a lâmina e com o outro puxando os dois últimos metâmeros abdominais para longe do corpo, saindo com eles os ovários (Fig. 5), sobre os quais se depositava uma gota de solução salina $0,9 \%$. Então, os ovaríolos foram separados, utilizando-se estiletes finos e examinados cuidadosamente sob lupa num aumento de $40 \mathrm{x}$, com luz transmitida. Para observação do pedicelo e estádio de deposição de vitelo no folículo, utilizamos uma quantidade pequena de detergente caseiro liquido (Ducke, 1960) juntamente com a solução salina, para reduzir a adesão entre os ovaríolos.

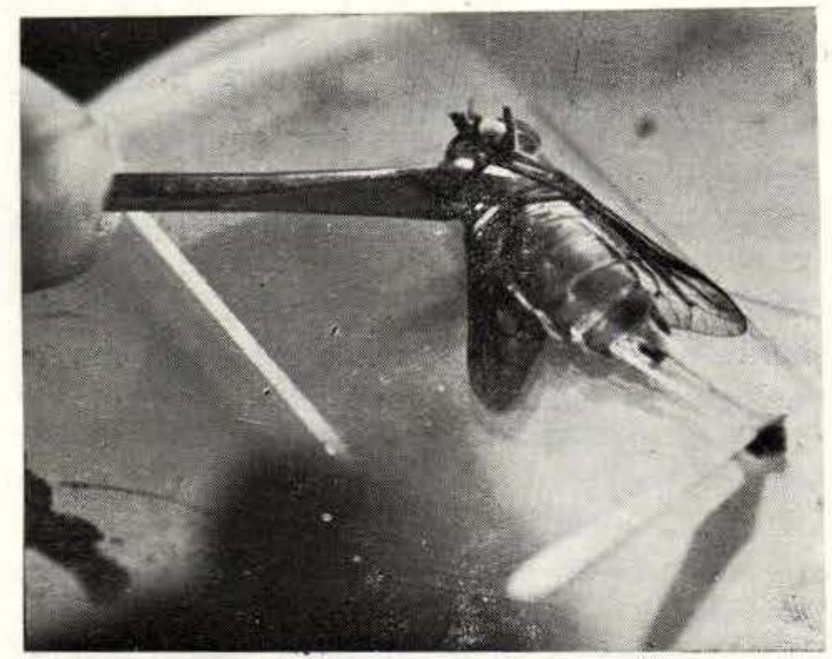

Fig. 5 - Separação dos ovários em Tabanus importunus, puxando os dois últimos metâmeros abdominais para longe do corpo.

A terminologia usada para o desenvolvimento do folículo, durante a ovogênese, é a de Christophers (1911), modificada por Mer (1936) (apud Detinova, 1962), para Culicidae mas aplicável a Tabanidae (Rockel, 1969; Anderson, 1971).

Os estádios de desenvolvimento são classificados de acordo com as seguintes características para Tabanidae: (Fig. 6) .
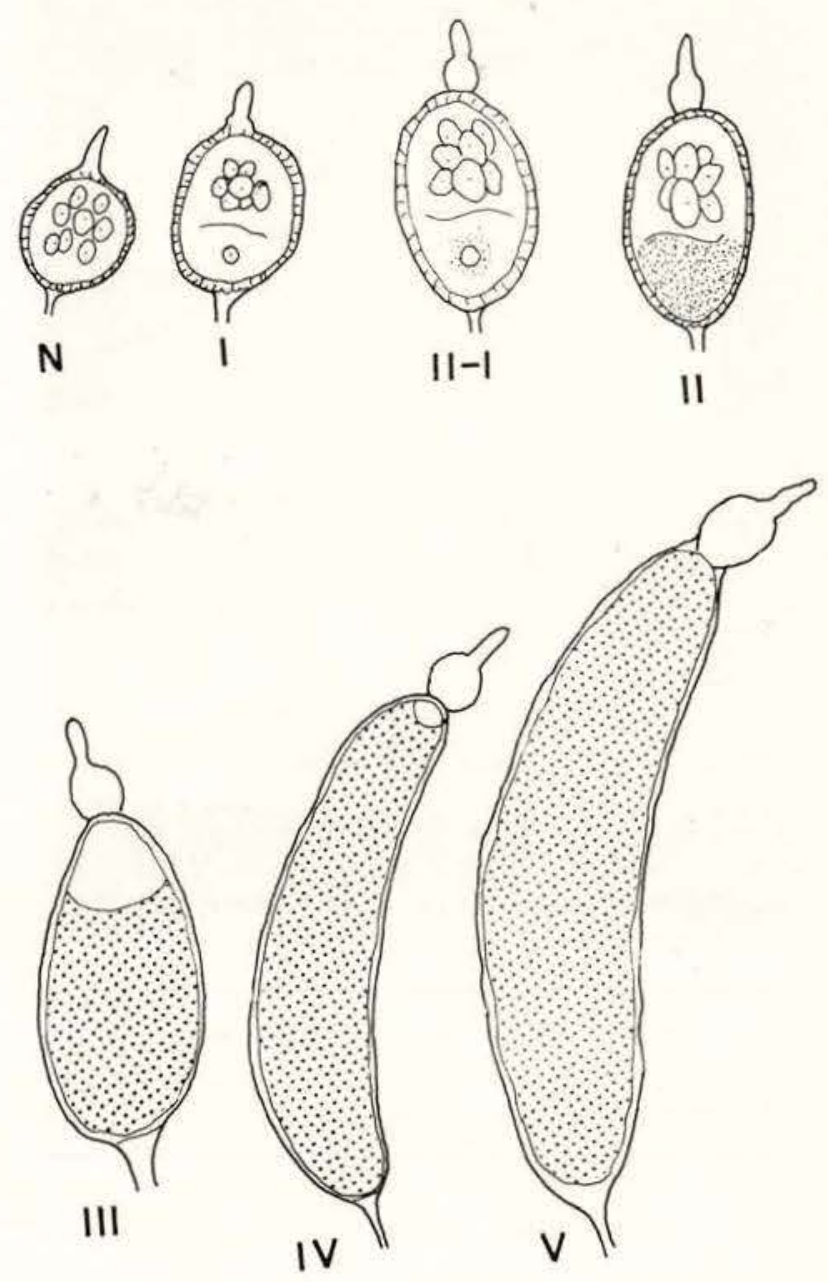

Fig. 6 - Representaçăo esquemática das fases de Christophers no desenvolvimento do folículo ovariano

$\mathrm{N}$ : O folículo apresenta-se esférico e com oito células indiferenciadas.

I : Um oócito evidente, situado na porção distal do folículo, sobre o qual se notam sete trofócitos.

I-II : Uma auréola de uma ou duas fileiras de grânulos de vitelo aparece ao redor do oócito. O folículo tende ao contorno oval.

II : Os grânulos vitelínicos tornam-se maiores e mais numerosos. O oócito passa a óvulo e cresce, tornando-se sensivelmente maior que os trofócitos, ocupando cerca de metade do folículo. 
: O óvulo passa a ocupar cerca de $3 / 4$ ou mais do folículo, não se conseguindo mais evidenciar o núcleo no meio da massa vitelínica. O folículo torna-se um tanto alongado.

IV : O folículo alonga-se e começa a ficar um pouco curvo, os trofócitos somente ocupam a extremidade proximal. O óvulo, cheio de vitelo, ocupa $9 / 10$ ou mais do folículo.

$\mathrm{V}$ : O cório cobre todo o óvulo. Os restos dos trofócitos encontram-se na extremidade proximal do folículo. O óvulo apresenta concavidade num lado e convexidade noutro e acha-se pronto para a fecundação e oviposição.

Determinação do número de ciclos gonotróficos (técnica de Polovodova).

Esta técnica aplicada para mosquitos (Detinova, 1962), para determinar o número de ciclos gonotróficos pode ser também aplicada às Tabonidae (Thomas, 1972; Magnarelli, 1976) e depende do fato de que, depois da oviposição uma pequena, mas distinta, dilatação permanece no local anteriormente ocupado pelo óvulo maduro. Esta dilatação retém restos de trofócitos e do epitélio folicular, constituindo o assim chamado "corpo amarelo".

Subseqüentes oviposições resultam em dilatações semelhantes; assim, após completar vários ciclos gonotróficos, uma série de dilatações podem ser vistas na porção do ovaríolo entre o folículo em desenvolvimento e o cálice. Estas dilatações podem ser percebidas sem corantes; para isso, é necessário que a luz incida por baixo do material, que é colocado sobre uma placa de vidro no suporte da lupa. Quando há muita incidência de luz superior, não há contraste nas dilatações, tornando-se mais difíceis as observações e podendo conduzir a erros de diagnósticos. Cuidados devem ser tomados para não romper o pedicelo; isto porque só é possível contar o número de dilatações quando - local de inserção do pedicelo no cálice for visível. Também, a ruptura do folículo deve ser evitada, visto, que os grânulos de vitelo, saindo do folículo, podem freqüentemente aderir ao pedicelo, tornando-se difícil a interpretação. Também a observação de um grande número de ovariolos em ambos os ovários faz-se neces- sária porque podem existir diferentes estádios de desenvolvimento e oniparidade.

Outro cuidado deve ser tomado quando o ovaríolo se encontra em estádio de saco. Com a saída do ovo maduro, no seu ponto de desenvolvimento e no pedicelo terminal, a íntima fica distendida formando uma dilatação denominada de saco. O tamanho deste saco corresponde ao comprimento do ovo e pedicelo terminal, quando recém-ocorrida a oviposição; assim sendo os corpúsculos amarelos não são observados, necessitando-se procurar cuidadosamente folículos que não se desenvolveram ou se degeneraram para se ter uma informação correta da idade fisiológica. Os estádios de saco são classificados em A, B, C e D, de acordo com sua contractabilidade. (Wilkes, 1976; Charlwood et al., s.d.).

Nas capturas com isca animal, o grau de contração pedicelar indica se a procura do hospedeiro, pelo inseto, se seguiu imediatamente à oviposição, ou não. Em nossos estudos, anotamos apenas dilatações em estádio $A$ dada a dificuldade de separar-se uma fase da outra, que é um tanto subjetiva, e também porque o tempo na contração deste saco é variável de individuo para individuo.

Ao lado do desenvolvimento normal, há alguns folículos que iniciam seu desenvolvimento e param em diferentes estádios de Christophers. O vitelo começa a aglomerar-se em massas esparsas pelo folículo, que se deforma, surgindo assim uma degeneraçäo folicular. Este foíículo não será ovipositado e o número de dilatação abaixo dele, se houver, corresponderá ao número de oviposições realizadas, sendo por conseguinte, muito útil na determinação da idade fisiológica.

Para comprovar anautogenia, trinta indivíduos de cada espécie, atraídos por cavalo, foram capturados antes de ter sugado sangue, mantidos em laboratório e alimentados com soluçäo de sacarose $10 \%$. Depois de quinze dias, foram dissecados e o estádio de desenvolvimento folicular foi registrado, tanto para as nulíparas quanto para as oníparas.

Para saber se as fêmeas nuíparas de Tabanidae que chegavam para o repasto sangüineo estavam fecundadas, ou não, as espermatecas de dez espécimens de cada espécie fo- 
ram examinadas sob microscópio para verificar a presença de espermatozóides. Cada espermateca foi cortada e depositada sobre uma lâmina com solução salina $0,9 \%$. O corte foi feite no duto da espermateca, bem próximo à espermateca propriamente dita e sobre esta depositada uma lamínula para posterior observação, com um grande aumento ao microscópio, $400 \mathrm{x}$.

Para determinar as possíveis intluências de fatores meteorulógicos com a variação sazonal e periodicidade diurna, lançou-se mão do coeficiente de correlação ( $r$ ), conforme indicado por Gomes (1977). Este mesmo teste foi feito para compararem-se as capturas entre armadiIhas de Malaise e armadilha com isca eqüina; para tanto, as capturas de Malaise foram agrupadas, duas a duas, e os dados das capturas com isca eqüina somente pegos os das 14:00 às 18:00 horas, isto porque, todas as coletas passaram por este horário e também por ser o de maior atividade de picada dos Tabanidae.

Oniparidade tanto sazonal quanto diária foi testada por qui-quadrado $\left(\mathrm{X}^{2}\right)$. Para efeito de cálculo, as coletas sazonais foram agrupadas duas a duas e as coletas diárias agrupadas de três em três, como se segue: 06:00 às 09:00, $09: 00$ às $12: 00,12: 00$ às $15: 00$ e $15: 00$ às $18: 00$ horas.

A sobrevivência entre as classes (nulípara a unípara, unipara a bípara e bípara a trípára) foi calculada em percentagem, isto é, (o $n^{\circ}$ de indivíduos de cada classe $/ \mathrm{n}^{0}$ de indivíduos da classe anterior) $\times 100$.

\section{RESUltados}

Trinta e duas espécies de mutucas foram coletadas durante o período de estudos. TrabaIharros com as quatro populações mais abundantes, sendo as possíveis de fornecerem dados mais fidedignos. Os resultados com as outras espécies serão publicados oportunamente, quando maior número for coletado.

A quantidade de machos capturados nas armadilhas foi tão pequena que deixamos de registrar a ocorrência.

\section{Variação sazonal em armadilha de Malaise}

Durante os meses de agosto/78 a agosto/ 79 , capturamos aproximadamente 5.700 individuos de $T$. dorsiger var. dorsovittatus, 580 de $T$. dorsiger var. modestus, 430 de $T$. importunus e 300 de $P$. cajennensis. A distribuição sazonal das quatro populações é mostrada na fig. 7 .

Da $T$, dorsiger var. dorsovittatus, podemos notar dois grandes picos, o primeiro em dezembro e o segundo em fevereiro e dois picos menores, no início e meados da coleta. Estes dois picos menores provavelmente são resultantes do pano novo colocado nestas armadilhas, nas respectivas datas.

A flutuação populacional de $T$. dorsiger var. modestus foi muito semelhante à variedade anterior, apenas ccorreu em menor número.

$T$. importunus apresentou apenas um pico populacional, de outubro a dezembro.

As três espécies acima foram registradas durante todo período de coieta.

$P$. cajennensis deixou de ocorrer de meados de dezembro a princípio de fevereiro e apresentou seu pico populacional nos meses de agosto e setembro.

Durante as capturas, duas vezes utilizamos tecido novo e verificamos que, justamente nestas duas épocas, houve maior número de Tabanidae capturado, no entanto o efeito do pano pareceu não proiongar-se por mais de duas ou três semanas, conseqüentemente não alterando o estudo da flutuação populacional.

Os dados de precipitação (média corrida entre cinco pontos), média mensal de temperatura e umidade relativa são mostrados na Fig. 8.

A correlação entre variação sazonal e precipitação, para as quatro populações, apresentou os seguintes valores de $r$ :

$$
\begin{array}{lrl}
\text { T. dorsiger var. dorsovittatus } & r=0,062 \\
\text { T. dorsiger var. modestus } & r=0,082 \\
\text { T. importunus } & r=0,231 \\
\text { P. cajennensis } & r=0,387\left({ }^{\prime}\right)
\end{array}
$$

(1) $-\mathrm{p}<0,05 ; 50$ g.l. 

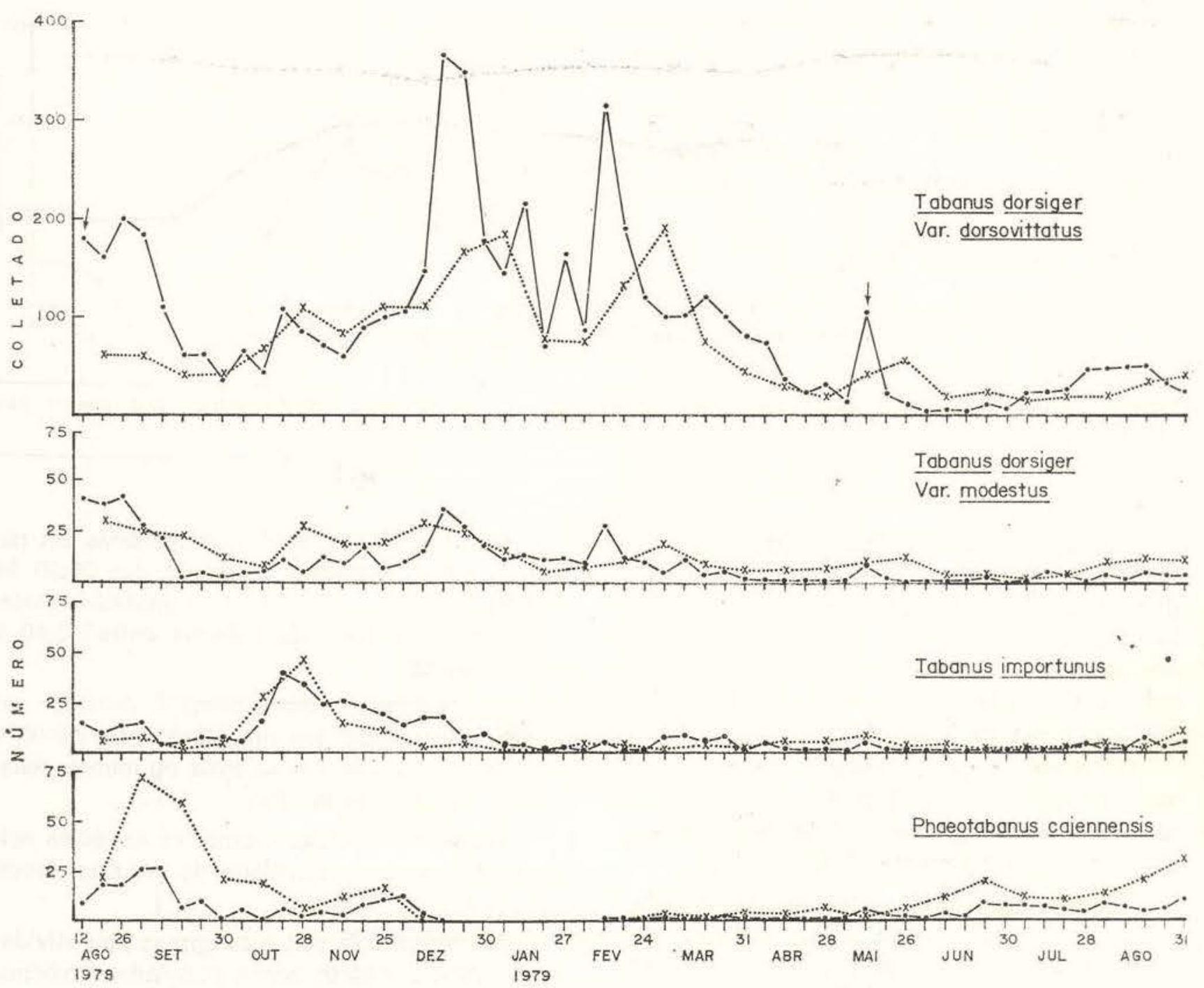

Fig. 7 - Variação sazonal de Tabanidae determinada por capturas semanais em armadilhas de Malaise (- - ) e quinzenais com isca eqüina (..x..) entre 14:00 - 18:00 hs, no Campus Universitário (Manaus).

Obs.: As setas indicam tecido novo na armadilha de Malaise.

Com estes valores, não podemos afirmar que existiu correlação para as primeiras populações, enquanto o resultado para $P$. cajennensis indicou a existência de uma correlação significativa $(p<0,05)$. Esta espécie deixou de ocorrer no início da estação chuvosa (dezembro) e começou a aparecer em meados da referida estação, subindo gradativamente (ver Figs. 7 e 8 ).

Para as quatro populações, não houve correlação de variação sazonal com temperatura e umidade relativa, isto em virtude de a tem- peratura média e umidade relativa, média de cada mês serem bastante uniformes, com pouca flutuação durante o ano.

\section{Variação sazonal em armadilhas com isca eqüina}

Nas capturas quinzenais utilizando isca eqüina, foram coletados cerca de 1700 exemplares de $T$. dorsiger var. dorsovittatus, 370 de $T$. dorsiger var. modestus, 200 de $T$. imporiunus e 370 de $P$. cajennensis. A distribuição sazonal destas espécies é mostrada na Fig. 7 . 


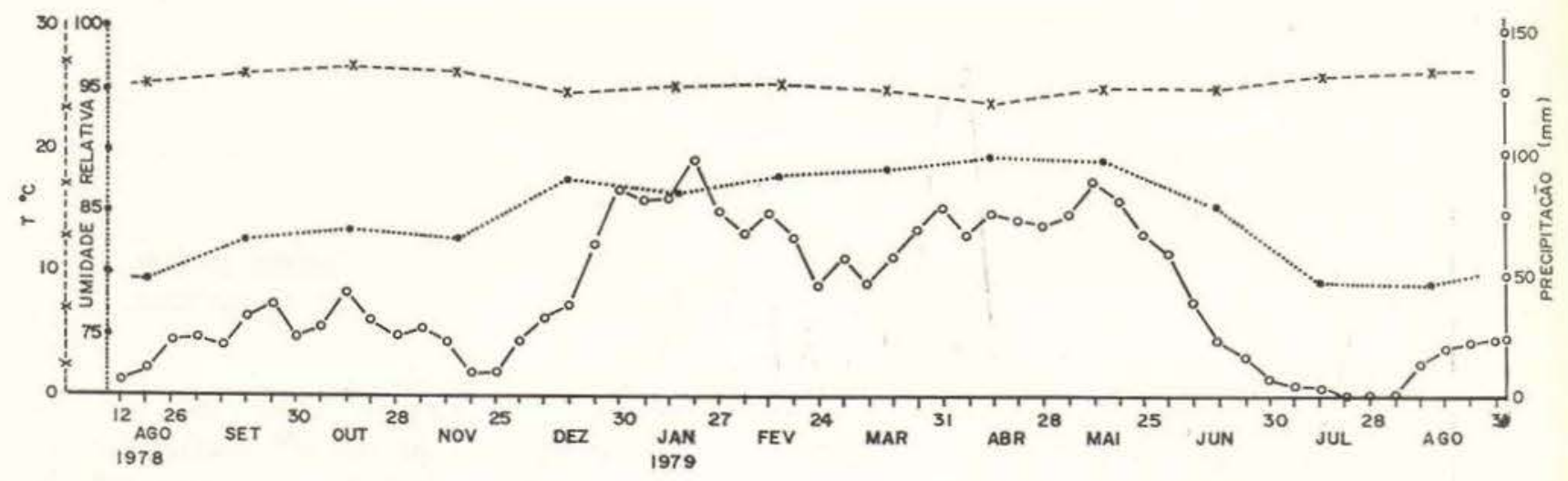

Fig. 8 - Médias mensais de temperatura $\left(\mathrm{T}^{\circ} \mathrm{C}\right)$, umidade relativa (UR) e média corrida entre cinco pontos para precipitação $(\mathrm{mm})$ durante os meses de coletas.

Para T. dorsiger var. dorsovittatus, podemos notar dois picos populacionais nos meses de dezembro e fevereiro, idênticos à captura com Malaise. Os dois picos menores detectados nas armadilhas de Malaise, provavelmente resultantes do pano novo, não foram verificados nas capturas com isca animal.

A população de $T$. dorsiger var. modestus iniciou em alta no princípio das coletas (agosto), decaiu, e de outubro a dezembro manteve um número relativamente alto.

$T$. importunus com apenas um pico populacional, marcadamente nítido em outubro, decaiu até dezembro e nos meses seguintes permaneceu com número baixo.

P. cajennensis, assim como nas armadilhas de Malaise, deixou de ser registrada de meados de dezembro a princípio de fevereiro, apresentando maior índice populacional em agosto e setembro.

\section{Periodicidade diurna}

A atividade diurna de picada das mutucas $(n=12)$ apresentou-se bastante clara nas capturas com isca eqüina (Fig. 9). Como pode ser visto, nenhuma das espécies mostrou ciclos diários bifásicos e todas apresentaram ápice maior de atividade, à tarde.

$T$. dorsiger var. dorsovittatus aumentou gradativamente das 06:00 às 09:00; a partir daí, manteve constante até às 12:00 e novamente subiu progressivamente até atingir um platô bem nítido entre 17:00 e 18:00 horas.
T. dorsiger var modestus manteve um número mais ou mencs constante das 06:00 às 14:00 horas; a partir daí subiu gradativamente, apresentando atividade máxima entre 16:00 e 18:00 horas.

$T$ importunus, assim como $T$. dorsiger var. modestus, apresentou um platô entre 16:00 e 18:00 horas, mantendo-se mais ou menos constante no restante do dia.

Para periodicidade diurna, as espécies acima apresentaram atividade de picadas desde 05:30 até 18:20 horas.

P. cajennensis somente apresentou atividade a partir das 08:00 horas, atingindo o máximo entre $15: 00$ e 16:00 horas.

A atividade dessas espécies diminuiram abruptamente a partir das 18:00 hs., terminando totalmente por volta das 18:20 horas.

Os dados diários de temperatura, umidade relativa e luminosidade são apresentados na parte inferior da Fig. 9.

Para todas as espécies, a atividade de vôo aumentou gradualmente durante o dia $(n=12)$ tingindo a média mais alta de moscas ativas entre $14: 00$ e 18:00 horas. Neste período, houve um forte declínio na intensidade de luz $(60.000-300$ lux $)$, pequena redução na temperatura $\left(30-27^{\circ} \mathrm{C}\right)$ e aumento na umidade relativa $(64-80 \%)$. Fazendo-se o teste de correlação com os fatores meteorológicos acima, para as quatro populações, nenhum resultado apresentou correlação a nível de 0,05 com 10 g.I. $(p>0,05)$. 


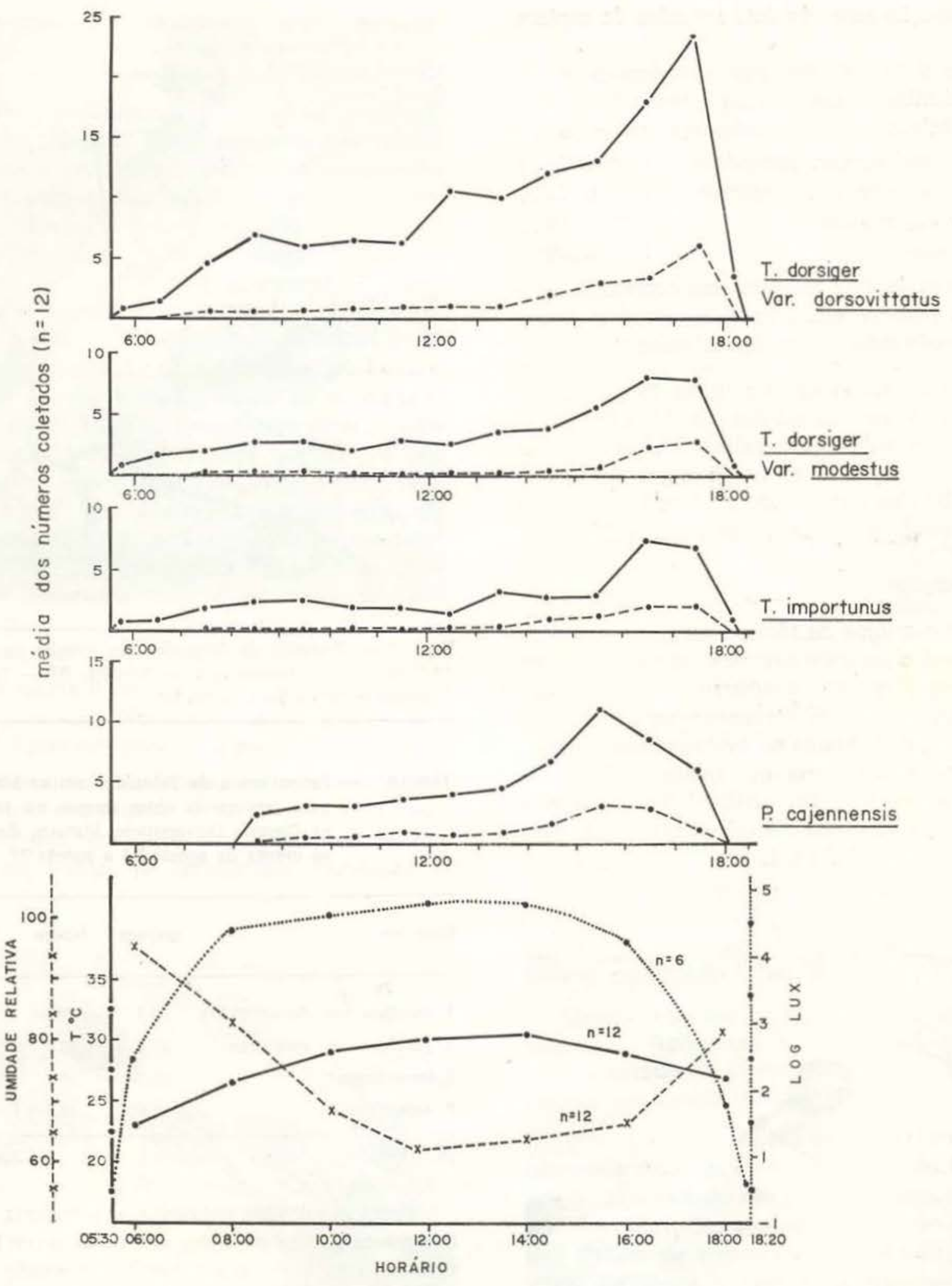

Fig. 9 - Ciclo diário de atividade das espécies mais abundantes de Tabanidae coletados no Campus Universitário através de armadilha de Malaise $(. . .$.$) e isca animal (- -) e as médias de temperatura, umidade relativa e in-$ tensidade de luz nos respectivos dias de coletas. 


\section{Comparação entre os dois inétodos de captura}

Os dois métodos são visivelmente muito semelhantes e quando feito o teste de correla. ção, obtivemos os seguintes resultados de $r$ :

T. dorsiger var. dorsovittatus $r=0,671\left({ }^{2}\right)$

T. dorsiger var. modestus $\quad r=0,702\left({ }^{2}\right)$

$T$. importunus $\quad r=0,768\left({ }^{2}\right)$

F. cajennensis $\quad r=0,879\left({ }^{2}\right)$

Estes valores indicam uma correlação altamente positiva entre os dois métodos utilizados, mostrando serem equivalentes.

Nota: Para efeito de cálculo, as coletas semanais em armadilhas de Malaise foram agrupadas quinzenalmente e os números das capturas com isca animal foram coletados entre 14:00 e 18:00 horas (horário de maior atividade de Tabanidae).

\section{Dissecações}

Os ovariolos de fêmeas nuliparas apresensentaram o pedicelo sem nenhuma dilatação ou grânulos (Fig. 10). Imediatamente após a oviposição, o pedicelo apresentou-se saculiforme (Fig. 11), dada asaída do óvulo maduro, ficando este saco com certa quentidade de material granular derivado do epitélio folicular. A proporção média de indivíduos em estádio de saco é mostrada na Tabela I.

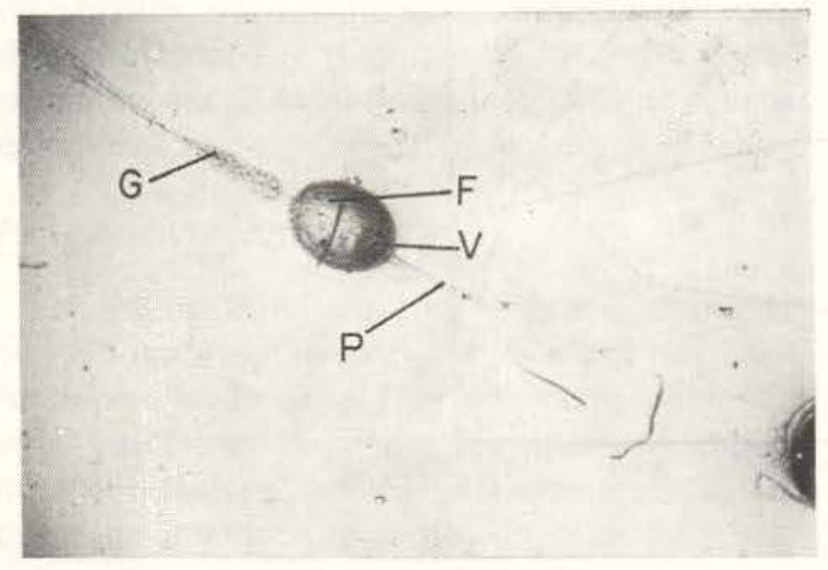

Fig. 10 - Ovaríolos de Tabanidae nulípara (50x). G germário: $\mathrm{F}$ - folículo; $\mathrm{P}$ - pedicelo; $\mathrm{V}$ - vitelo.

(2) $-p<0.01 ; 25$ g.l.

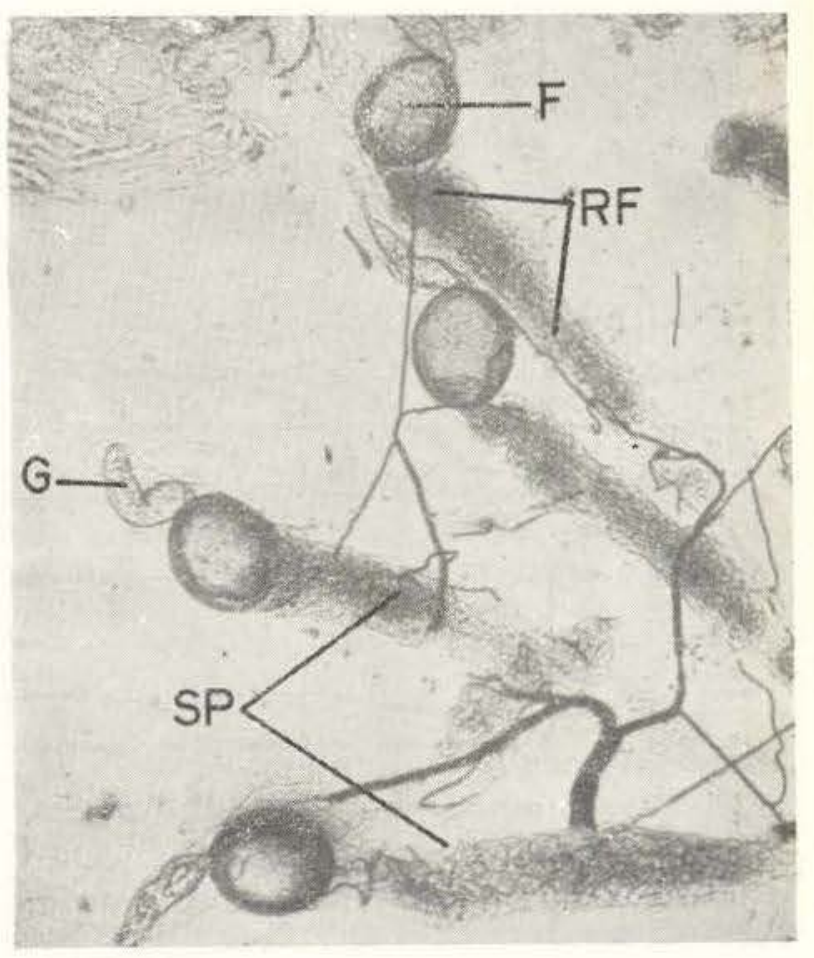

Fig. 11 - Ovariolos de Tabanidae em estádio de saco "A" $(50 x)$. G - germário; $F-$ folículo; RF - restos foliculares; SP - saco pedicelar.

TABELA 1 - Percentagem de Tabanidae em estádio de saco procurando obter sangue em cavalo no Campus Universitário, Manaus, durante os meses de agosto/78 a agosto $/ 79$

Espécies

unípara bipara Total

T. dorsiger var. dorsovittatus

$\begin{array}{lll}9,4 & 28,8 & 12,2\end{array}$

T. dorsiger var. modestus

$21,4 \quad 36,4$

25,2

T. importunus

$19,2 \quad 31,2$

22,7

P. cajennensis

$6,4 \quad 28,8$

11,8

Estes resultados indicam que a maioria dos indivíduos destas espécies não procura um hospedeiro, logo após a oviposição, passando por um período de descanço. Ou, se procura, demora a encontrá-lo, dando tempo suficiente para a contração do saco pedicelar. Entre estas classes, encontramos uma prpoporção maior de 
estádio de saco em bíparas o que pode $\overline{d e}$ monstrar uma resposta mais rápida à procura de hospedeiro nas fêmeas mais velhas.

Posteriormente, processa-se a contração do saco pedicelar e os detritos do seu interior tornam-se conspícuos dentro de aproximadamente vinte e quatro horas, formando um distinto "corpo amarelo" (Fig. 12). A primeira dilatação no pedicelo fica próxima ao folículo. Quando há duas dilatações, a primeira corresponde à mais distante do folículo e mais distante ainda quando completa três ciclos gonotróficos (Fig. 13). Com a prática, essas dilatações são facilmente visíveis se as dissecações forem realizadas cuidadosamente. Tanto dilatações bem pigmentadas quanto não pigmentadas foram encontradas num mesmo ovário. As últimas dilatações do pedicelo, que correspondem às primeiras oviposições, normalmente se apresentam mais claras, sem muito pigmentos, dada a passagem do óvulo pelo oviduto comum que carrega parte dos pigmentos, por ocasião da oviposição.

A tabela II apresenta os resultados das dissecações nas diferentes classes e o número total dissecado para cada espécie.

Nenhuma das fêmeas examinadas foi encontrada em estádio $\mathrm{N}$ de Christophers, mostrando que todas que chegam para obter sangue no animal já apresentam deposição de

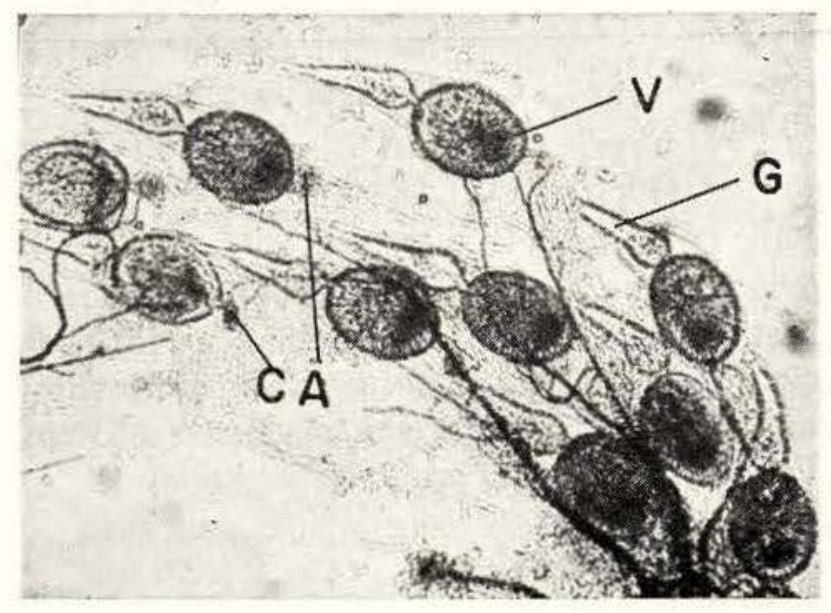

Fig. $12-$ Ovariolos de Tabanidae unipara (50x). CA restos foliculares agregados formando o "corpo amarelo"; G - germário; V - vitelo.

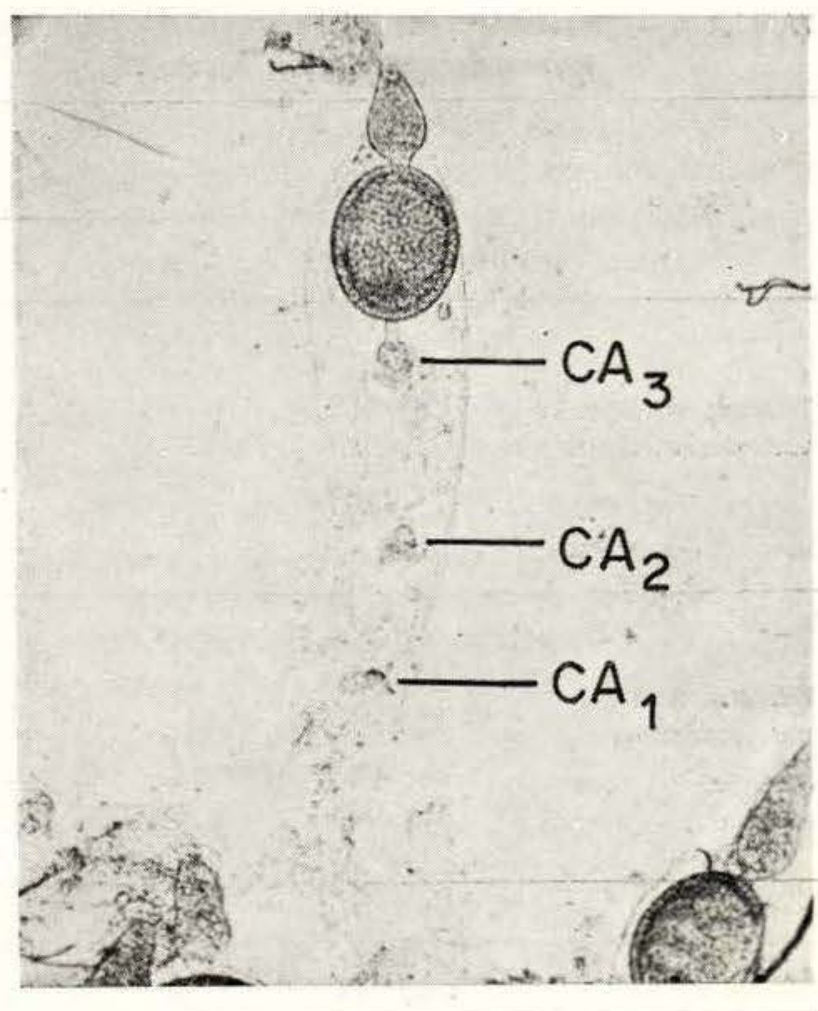

Fig. 13 - Ovariolo de Tabanidae tripara, mostrando os "corpos amarelos" de três oviposições $\left(\mathrm{CA}_{1}, \mathrm{CA}_{2}\right.$ e $\mathrm{CA}_{3}$ ) (50x).

vitelc no oócito, sendo encontrada a maioria em estádio II de Christophers.

Exceção se fez para as que chegaram em estádio de saco, nas quais a maioria das três espécies do gênero Tabanus tinha o folículo em estádio $\mathrm{I}-\mathrm{II}$, enquanto $P$. cajennensis tinha a maioria em estádio I (ver Tabela II).

Observamos que as fêmeas mantidas com sangue em laboratório, quando tinham os óvulos em estádio $V$, já apresentavam o próximo folículo em estádio I ou I-II (Fig. 14) .

Dentro de cada classe de idade fisiológica, apresentaram mais deposição de vitelo as com corpos amarelos do que as em estádio de saco (ver Tabela II), isto porque maior tempo se passou depois da oviposição e a deposição de vitelo continuou a realizar-se, mostrando ser um processo contínuo até atingir estádio II de Christophers.

Fêmeas nulíparas foram abundantes e nenhum indivíduo dissecado em $T$. dorsiger var. dorsovittatus, $T$. dorsiger var. modestus e $P$. 
TABELA II - Resultados das dissecaçōes de Tabanidae capturadas no Campos Universitário, Manaus, durante os meses de agosto/78 a agosto/79

\begin{tabular}{|c|c|c|c|c|c|c|c|c|}
\hline \multirow[t]{2}{*}{ Espécie } & & \multicolumn{5}{|c|}{$\begin{array}{l}\text { Tabanidae capturadas nos diferentes } \\
\text { estádios de desenvolvimento do folículo }(\%)\end{array}$} & \multirow{2}{*}{\multicolumn{2}{|c|}{$\begin{array}{l}\text { Total dissecado } \\
\text { em cada classe }\end{array}$}} \\
\hline & & $\mathrm{N}$ & 1 & $1-11$ & II & III-V & & \\
\hline $\begin{array}{l}\text { Tabanus dorsiger } \\
\text { var. dorsovittatus }\end{array}$ & $\begin{array}{l}\text { Nulip. } \\
\text { Unip. ES } \\
\text { Unip. CA } \\
\text { Bip. ES } \\
\text { Bip. CA }\end{array}$ & $\begin{array}{l}- \\
- \\
- \\
-\end{array}$ & $\begin{array}{r}1,25 \\
20,59 \\
1,11 \\
17,65 \\
-\end{array}$ & $\begin{array}{r}8,30 \\
52,94 \\
11,70 \\
58,82 \\
16,95\end{array}$ & $\begin{array}{l}89,90 \\
26,47 \\
87,19 \\
23,53 \\
83,05\end{array}$ & $\begin{array}{c}0,55 \\
- \\
- \\
- \\
-\end{array}$ & $\begin{array}{r}723 \\
34 \\
359 \\
17 \\
59\end{array}$ & 393 \\
\hline $\begin{array}{l}\text { Tabanus dorsiger } \\
\text { var. modestus }\end{array}$ & $\begin{array}{l}\text { Nulip. } \\
\text { Unip. ES } \\
\text { Unip. CA } \\
\text { Eip. ES } \\
\text { Bip. CA }\end{array}$ & $\begin{array}{l}- \\
- \\
-\end{array}$ & $\begin{array}{c}1,71 \\
19,05 \\
- \\
33,33 \\
-\end{array}$ & $\begin{array}{r}6,86 \\
66,67 \\
9,18 \\
41,67 \\
9,10\end{array}$ & $\begin{array}{l}91,43 \\
14,28 \\
90,82 \\
25,00 \\
90,90\end{array}$ & $\begin{array}{l}- \\
- \\
- \\
-\end{array}$ & $\begin{array}{r}173 \\
21 \\
98 \\
12 \\
33\end{array}$ & 119 \\
\hline Tabanus importunus & $\begin{array}{l}\text { Nulip. } \\
\text { Unip. ES } \\
\text { Unip. CA } \\
\text { Bip. ES } \\
\text { Bip. CA } \\
\text { Trip. ES } \\
\text { Trip. CA }\end{array}$ & $\begin{array}{l}- \\
- \\
- \\
- \\
-\end{array}$ & $\begin{array}{c}\overline{10,00} \\
- \\
- \\
- \\
-\end{array}$ & $\begin{array}{r}- \\
40,00 \\
5,77 \\
70,00 \\
6,25 \\
- \\
25,00\end{array}$ & $\begin{array}{c}97,65 \\
50,00 \\
94,23 \\
30,00 \\
93,75 \\
- \\
75,00\end{array}$ & $\begin{array}{c}2,35 \\
- \\
- \\
- \\
- \\
-\end{array}$ & $\begin{array}{l}85 \\
10 \\
52 \\
10 \\
32 \\
-\end{array}$ & $\begin{array}{r}42 \\
4\end{array}$ \\
\hline $\begin{array}{l}\text { Fhaeotabanus } \\
\text { cajennensis }\end{array}$ & $\begin{array}{l}\text { Nulip. } \\
\text { Unip. ES } \\
\text { Unip. CA } \\
\text { Bip. ES } \\
\text { Bip. CA }\end{array}$ & $\begin{array}{l}- \\
- \\
- \\
-\end{array}$ & $\begin{array}{r}2,30 \\
75,00 \\
5,60 \\
54,54 \\
13,89\end{array}$ & $\begin{array}{l}13,30 \\
25,00 \\
14,40 \\
36,36 \\
16,67\end{array}$ & $\begin{array}{r}84,40 \\
- \\
80,00 \\
0,10 \\
69,44\end{array}$ & $\begin{array}{l}- \\
- \\
- \\
-\end{array}$ & $\begin{array}{r}173 \\
8 \\
125 \\
11 \\
36\end{array}$ & 133 \\
\hline $\begin{array}{l}\text { dip. = nuliparo. } \\
=\text { estádio de sac }\end{array}$ & & & D. & ara. & & Tota & $=2075$ & \\
\hline
\end{tabular}

cajennensis foi encontrado com mais de dois ciclos de oviposiçōes; é possível que sejam formados e esta possibilidade deve ser cuidadosamente investigada em outras áreas. Apenas $T$. importunus, a maior das espécies, apresentou quatro individuos $(1,0 \%)$ com três ciclos completados, procurando obter sangue para iniciar o $4^{9}$ ciclo gonotrófico e conseqüentemente apresentando maior longevidade. É possivel que alguns completem quatro, mas não sobrevivem para iniciar o que seria o quinto ciclo. Mesmo que cada espécie realize poucas oviposiçōes, o número de ovos colocados é bastante alto, dando uma média $(n=15)$, por ovário, de: 190 em $T$. dorsiger var. dorsovittatus, 183 em $T$. dorsiger var. modestus, $350 \mathrm{em}$ $T$. importunus e $140 \mathrm{em} P$. cajennensis.

\section{Indice de sobrevivência}

Para efeito de cálculo, consideramos a sobrevivência de nuliparas $100 \%$ e, com base nisso, obtivemos índices para as diferentes classes, conforme mostra a Tabela III. 


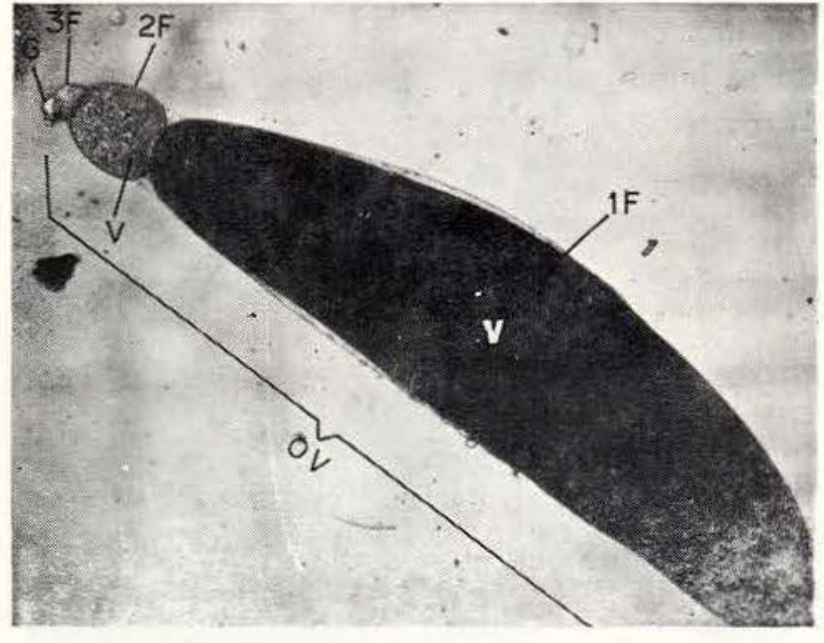

Fig. 14 - Ovaríolo mostrando três fases da ovogênese $(1 \mathrm{~F}, 2 \mathrm{~F}$ e $3 \mathrm{~F})$ e o segundo folículo $(2 \mathrm{~F})$ com deposiçăo de vitelo já em estádio I. II de Christophers antes da oviposição. G - germário; OV - ovariolo: V - vitelo.

TABELA III - Índice de sobrevivência para as espécies de Tabanidae capturadas no Campus Universitário, Manaus, durante os meses de agosto $/ 78$ a agosto $/ 79$

$\begin{array}{ccc}\text { nulipara à } & \text { unipara à } & \text { bípara à } \\ \text { unipara } & \text { bipara } & \text { trípara }\end{array}$

\begin{tabular}{llll}
$\begin{array}{l}\text { T. dorsiger var. } \\
\text { dorsovittatus }\end{array}$ & $56,14 \%$ & $15,82 \%$ & 0,0 \\
$\begin{array}{l}\text { T. dorsiger } \\
\text { var. modestus }\end{array}$ & $70,4 \%$ & $37,8 \%$ & 0,0 \\
$\begin{array}{l}\text { T. importunus } \\
\text { P. cajennensis }\end{array}$ & $73,0 \%$ & $67,8 \%$ & $9,5 \%$ \\
\hline
\end{tabular}

Segundo estes resultados, podemos ver que $T$. importunus apresentou índice de sobrevivência mais alto e conseqüentemente maior longevidade. Nas outras espécies, o índice de sobrevivência decaiu abruptamente na passagem para bípara, nenhuma atingindo a classe seguinte (trípara).

\section{Retenção de óvulos}

A retenção de óvulos é a mais óbvia indicação de que uma fêmea é onípara (Fig. 15).
Infelizmente, nem todas retém óvulos depois da cviposição e somente pela retenção, não podemos saber o número de oviposições realizadas. A retenção para as espécies estudadas é mostrada na Tabela IV, onde notamos mais bíparas que uníparas retendo óvulos.

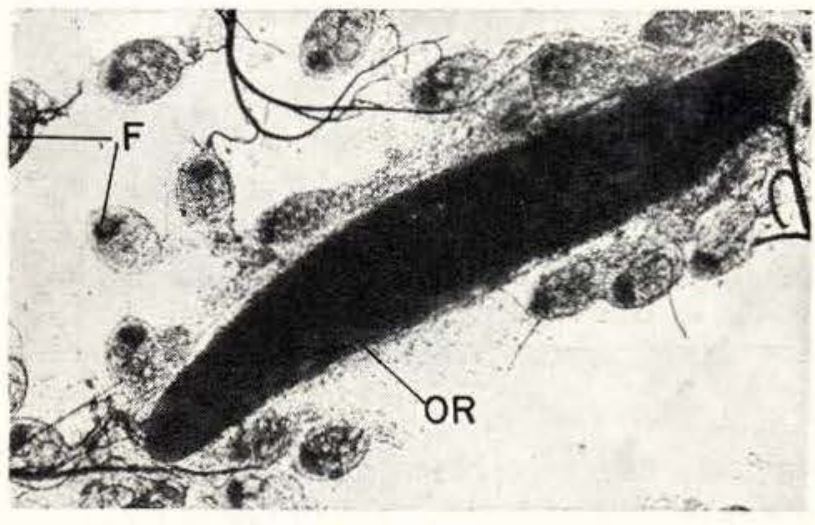

Fig. 15 - Óvulo retido (OR) em estádio $V$ juntamente com outros folículos (F) em estádio II. (50x).

TABELA IV - Retenção de óvulos por fêmeas de Tabanidae capturadas com isca eqüina no Campus Universitário, Manaus, durante os meses de agosto/78 a agosto/79

\begin{tabular}{lccc} 
Espécie & $\%$ uníparas & $\%$ bipara & $\%$ onípara \\
\hline $\begin{array}{l}\text { T. dorsiger } \\
\begin{array}{l}\text { var. dorsovittatus } \\
\text { T. dorsiger }\end{array}\end{array}$ & 13,9 & 20,7 & 15,0 \\
$\begin{array}{l}\text { var. modestus } \\
\text { T. importunus }\end{array}$ & 12,6 & 24,8 & 15,8 \\
\begin{tabular}{l} 
P. cajennensis \\
\hline
\end{tabular} & 5,1 & 24,4 & 19,8 \\
\hline
\end{tabular}

\section{Degenerações}

Degenerações foliculares (Fig. 16) são tacilmente conhecidas, em face da forma irregular da dilatação e presença de vitelos agregados em massas frouxas por todo o folículo. 0 número de degenerações presentes nos ovários sempre foi reduzido (nunca encontramos mais de, três em cada ovário) e a maioria das fêmeas 


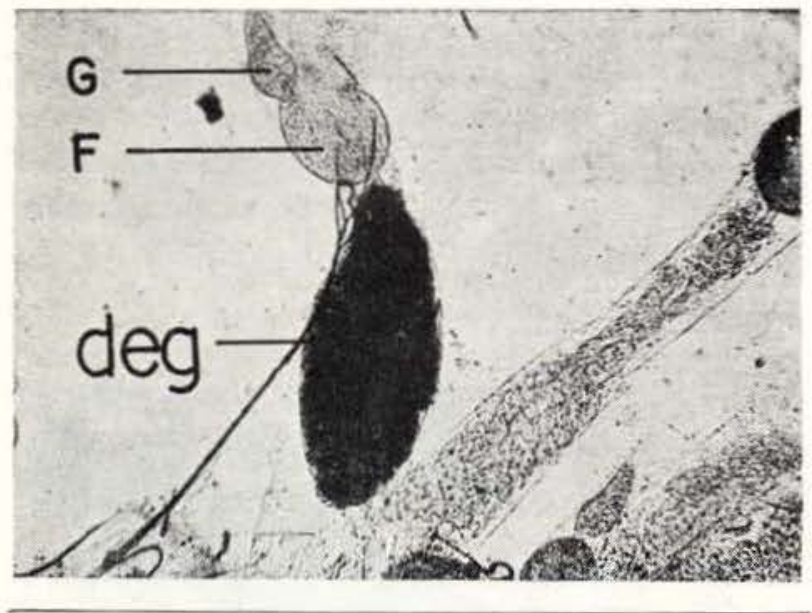

Fig. 16 - Ovaríolo com degeneração (deg) e outro em estádio de saco "A". (50x).

oniparas nāo as apresentam, sugerindo assim que obtem quantidade suficiente de sangue para a maturação de todos oócitos, ou a maturação ocorre proporcionaimente à quantidade de sangue obtida. Em nossas dissecações, encontramos folículos que não se desenvolveram (Fig. 17). Dado este fenômeno, quando se quer determinar o número de oviposições, faz-se necessário observar vários folículos de ambos os ovários para diminuir ou eliminar possíveis erros.

\section{Fecundação}

Nas dez fêmeas nuliparas dissecadas, das diferentes espécies de mutucas, sempre foi verificada a presença de espermatozóide na espermateca. Estes apresentavam-se como finos filamentos em forma de agulha biaculeada. A cópula, por conseguinte, ocorre antes da primeira obtenção de sangue.

\section{Anautogenia}

Nenhuma das vinte e cinco fêmeas de cada espécie que foi alimentada em laboratório por quinze dias com solução de sacarose $10 \%$, desenvolveu seus folículos além do estádio II, comprovando-se assim, que as espécies estudadas são anautógenas e apresentando um ciclo, como o da Fig. 18.

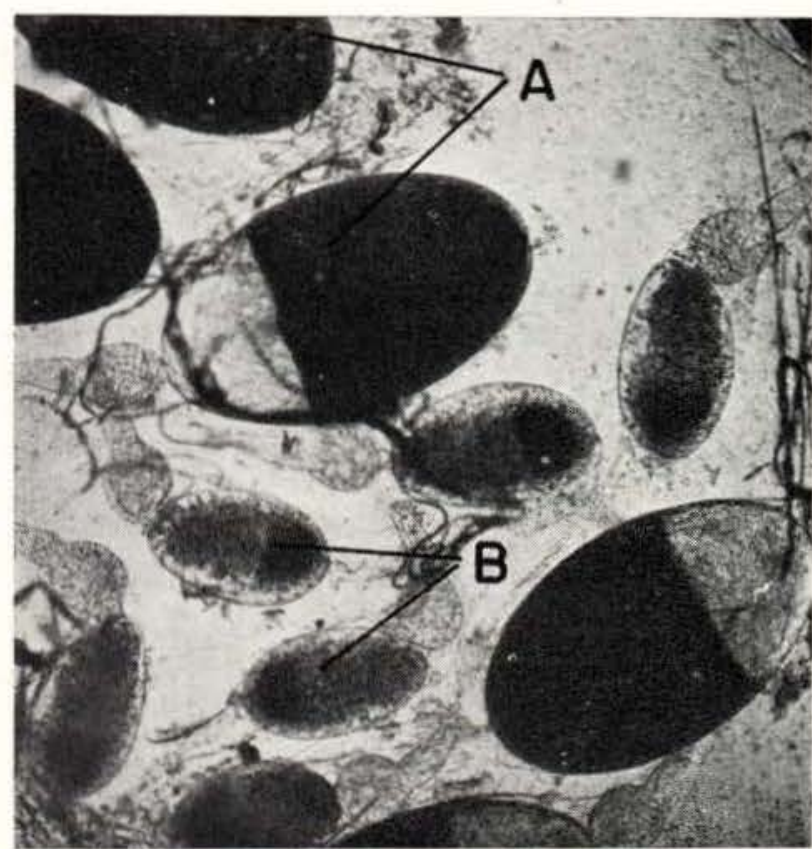

Fig. 17 - Ovariolo em diferentes estádios da ovogênese $(50 x)$. A - estádio III, em desenvolvimento. B estádio II, em descanço.

Nos ápices populacionais, (ver Fig. 7) a quantidade de nulíparas foi elevada, evidenciando mais uma vez a anautogenia nas espécies estudadas.

\section{Oniparidade sazonal}

$\mathrm{Na}$ Fig. 19 podemos ver o índice de oniparidade sazonal das espécies estudadas, notando-se que quando predominaram fêmeas oníparas houve um baixo número detectado tanto nas armadilhas de Malaise quanto em armadiIha com isca eqüina. Normalmente, o índice de nulíparas na população se manteve acima de $60 \%$, durante o ano.

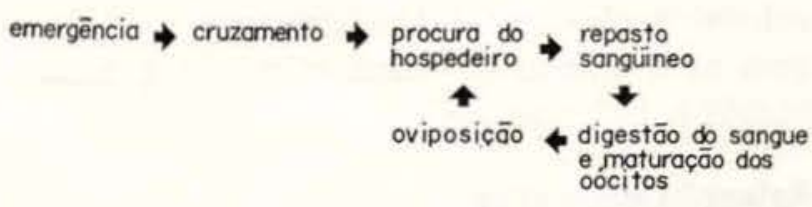

Fig. 18 - Padrão do ciclo gonotrófico em Tabanidae anautógenas. 

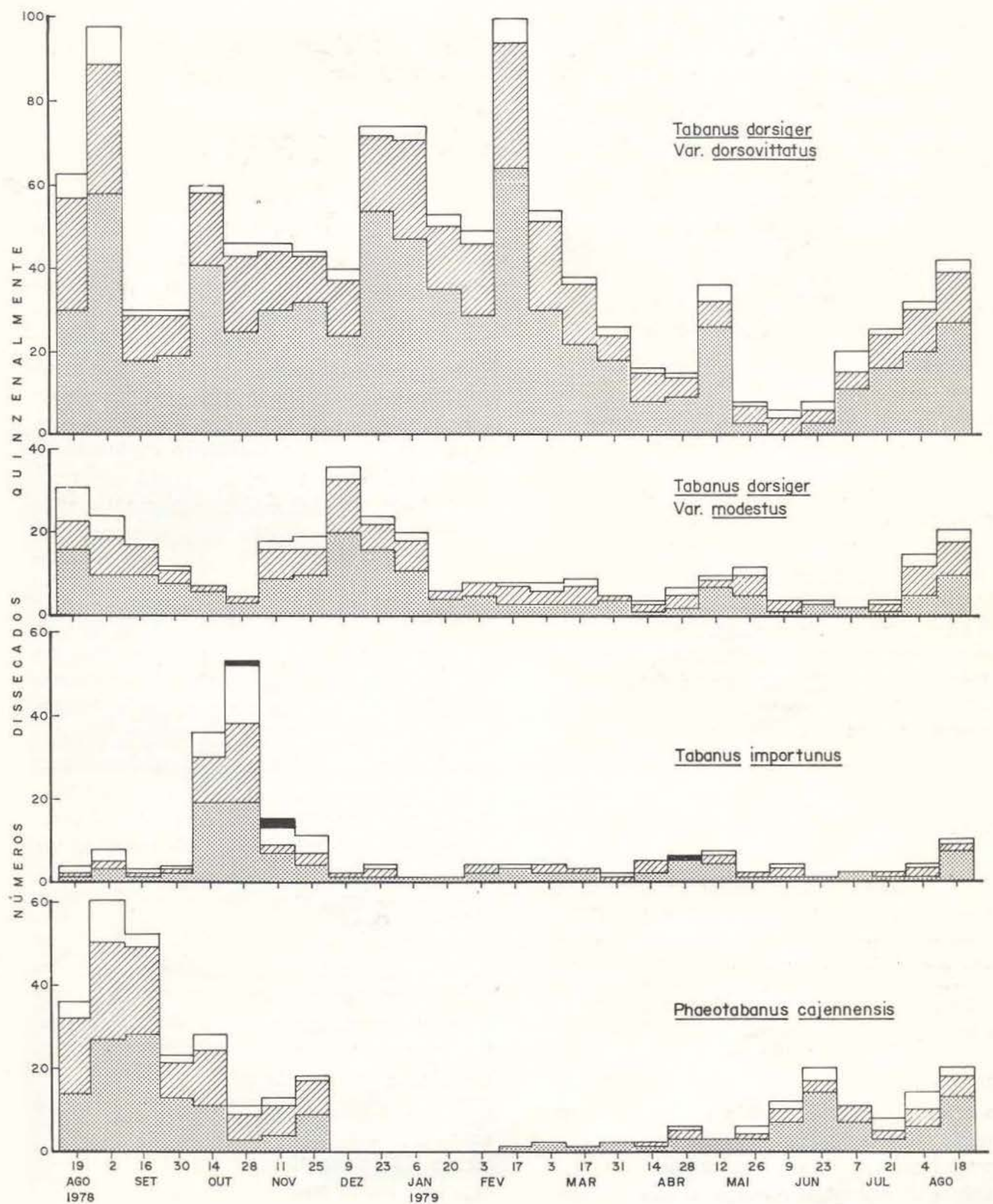

Fig. 19 - Número total de Tabanidae dissecados, indicando a oniparidade sazonal das espécies mais abundantes atraídas por cavalo no Campus Universitário (Manaus), em capturas quinzenais.

鹿-Nuliparas $\square$ - Uniparas -Triparas

Idade... 
Para P. cajennensis foi comprovada uma estação de vôo bem defínida, (agosto - outubro) na qual predominaram indivíduos nuliparas. Como esta espécie deixoli de ocorrer de meados de dezembro a princípio de fevereiro, podemios concluir que esta é uma espécie uni. voltina. Quanto às demais do gênero Tabanus que foram registradas todos os meses durante o ano, parecem completar mais de um ciclo populacional ou então apresentam um ciclo irregular dadas as grandes variações no desenvolvimento do estádio larval, conduzindo a emergências de adultos durante todo o ano.

0 teste de qui-quadrado não apresentou diferença significativa para oniparidade sazonal $(p>0,05)$. Isto dá mais um indício de contínua emergência de indivíduos na população.

\section{Oniparidade diária}

Diferença na oniparidade diária, através do teste de qui-quadrado $\left(x^{2}\right)$, não foi verificada; não ficando desse modo comprovadas as atividades diferentes entre as fêmeas nuliparas e oníparas para as espécies estudadas.

\section{Ciclo gonotrófico}

Em condições de laboratório, com repasto sangüineo completo, a maturação dos folículos foi uniforme para as espécies consideradas, as quais desenvolveram totalmente os oócitos até estádio V, em cinco dias (120 hs.). Na Fig. 20, podemos ver as etapas de deposição de vitelo em diferentes dias.

Se a oviposição ocorrer vinte e quatro horas após o desenvolvimento do folículo e o inseto imediatamente sair à procura do hospedeiro (como verificamos através de fêmeas em estádio de saco), o ciclo gonotrófico tem duração mínima de seis dias. Se algum atraso ocorrer face a condições meteorológicas ou dificuldade de encontrar o hospedeiro, este tempo pode ser maior, variando de indivíduo a indivíduo. Todas as tentativas de oviposição em laboratório, mesmo seguindo os métodos descritos por Roberts (1966), MacClain et al. (1975), e Magnarelli \& Anderson (1979) foram frustradas. Sabemos que, com cinco dias, o óvulo está totalmente desenvolvido, pronto para oviposição.

\section{Discussão}

Acreditamos ter escolhido um local adequado para as coletas de Tabanidae porque as armadilhas foram montadas em lugar alagado, sendo o mais indicado para detectar período de emergência e flutuação populacional, pois segundo Oldroyd (1973) as larvas de Tabanidae são predominantemente aquáticas ou semiaquáticas e os adultos são particularmente mais abundantes próximo aos rios, lagos e lugares alagados. O alto número capturado de mutucas durante o ano, deve-se à constante emergência de adultos, comportamento ativo de procura do hospedeiro ou dispersão, bem como à proximidade da armadilha ao !ocal de reprodução, o que concorda com DeFoliart et al. (1967).

A orientação visual de Tabanidae pelas cores varia de espécie a espécie e requer que o inseto possa discriminar a cor, do fundo contrastante. Esta condição para atração visual é satisfeita quando há um maior ou menor contraste do que o fundo (Bracken et al. 1962). Em nossas armadilhas, este contraste foi acentuado, mesmo depois de o tecido tornar-se um tanto pálido em virtude da exposição constante ao tempo (Fig. 1).

Quando foi colocado tecido novo, dadas as avarias dos velhos, o contraste se acentuou durante aproximadamente três semanas e provavelmente influenciou o número de insetos capturados durante aquele curto período. Como esse período não atingisse um mês, não deve ter alterado os resultados da variação sazonal, pois o estudo foi conduzido por treze meses (56 semanas) com os dois métodcs de capturas, sendo que, em armadilha com isca eqüina, este pequeno ápice não foi verificado. Acreditamos que a perda de eficiência, em armadilha de Malaise, deve ser considerada somente em estudos críticos de biologia e ecologia. 

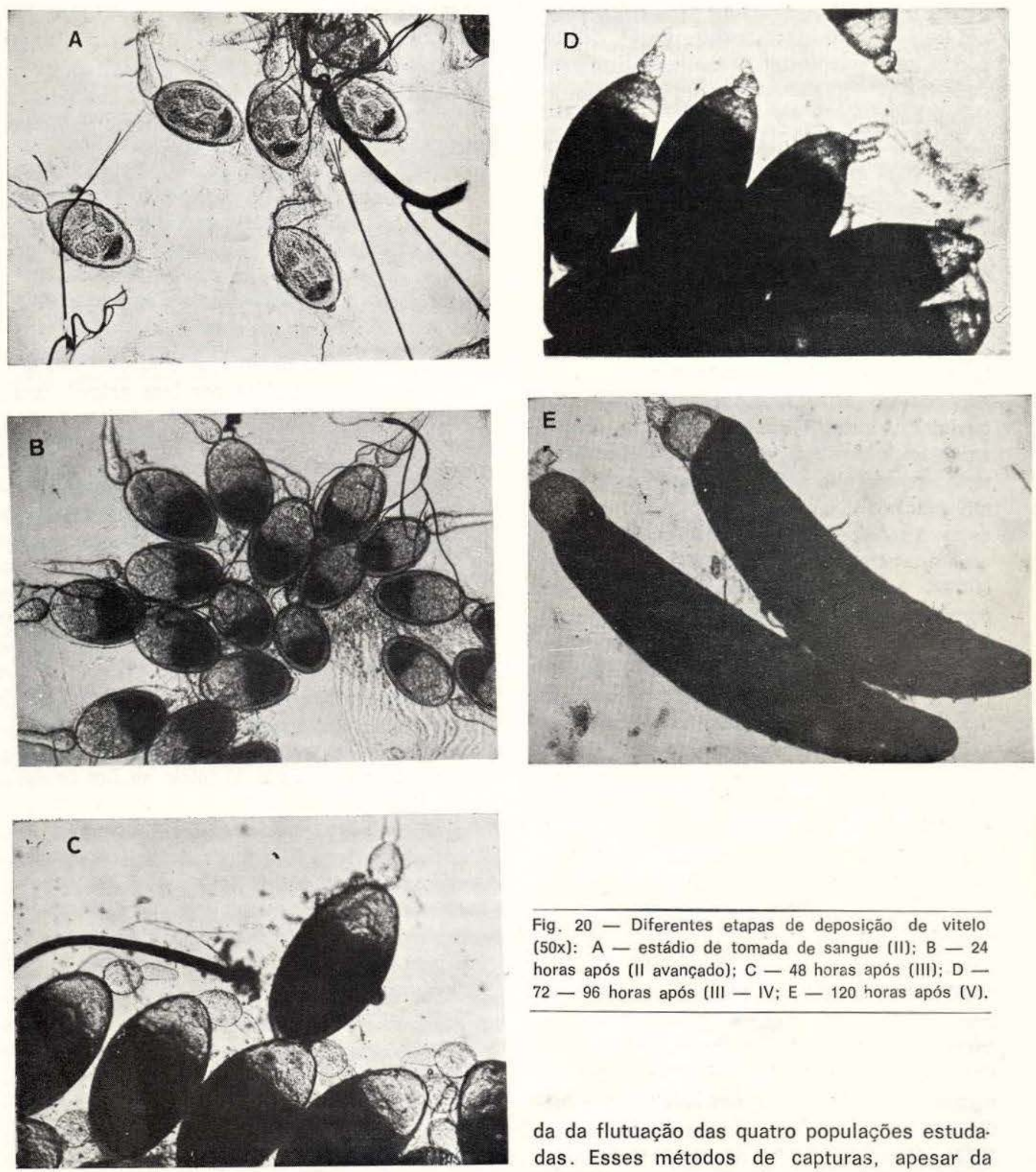

Fig. 20 - Diferentes etapas de deposiçăo de vitelo (50x): A - estádio de tomada de sangue (II): B -24 horas após (II avançado); C -48 horas após (III); D $72-96$ horas após (III - IV; E - 120 horas após (V).

A comparação entre os métodos de coletas, armadilhas de Malaise e armadilha com isca eqüina, mostrou-se altamente correlacionada $(P<0,01)$, dando uma estimativa adequa-

da da flutuação das quatro populações estuda. das. Esses métodos de capturas, apesar da remoção permanente de parte da população, não influenciaram o estudo da periodicidade diurna, pois sempre os ápices de atividades foram registrados à tarde, quando grande número já havia sido coletado. Também dificilmente influenciou na variação populacional,

Idade... 
porque as larvas são consideradas como de vida longa e univoltinas, enquanto os adultos apresentam vida curta. O que estes métodos poderiam ter influenciado, eventualmente seria na oniparidade sazonal, dada a retirada de parte da população, não permitindo às fêmeas atingirem o máximo de ciclos gonotróficos. No entanto, estudos antes de iniciar as coletas definitivas e após o término, mostraram os mesmos índices de baixa oniparidade; por conseguinte, não devem explicar-se estes resultados baseado nos métodos de coletas.

Apesar de muitos aspectos de Tabanidae, tal como padrão de dispersão e estratégia de encontrar o hospedeiro, não serem muito entendidos (Thorpe \& Hansens, 1978), o gradual aumento de número de mutucas capturadas à tarde, sugere que neste horário há uma maior atividade de dispersão ou procura do hospedeiro. Esses resultados são semelhantes aos encontrados por Roberts (1974) e Dale \& Axtell (1975). Se as espécies estudadas estivessem correlacionadas com níveis intermediário de luz, temperatura e umidade relativa, poder-seia esperar ciclos bifásicos, o que nẳo foi verificado. A relativa importância de fatores meteorológicos afetando atividade de Tabanidae parece ser, pelo menos parcialmente, dependente do local das coletas, tipo de armadilha, bem como das espécies envolvidas. Alverson \& Noblet (1977) registraram pressão barométrica e temperatura influenciando a atividade de tabânidas. Burnett \& Hayes (1974) registraram pressão barométrica, temperatura e evaporação como os fatores que mais influenciam. Ambos os trabalhos foram realizados em regiōes temperadas, sujeitas a variações extremas. A região em que realizamos o estudo, norte do Brasil, próximo ao equador, é caracterizada por apresentar temperaturas médias mensais superior a $22^{\circ} \mathrm{C}$, umidade relativa média em torno de $80 \%$ durante o ano (IBGE, 1977). Contribuem para manter a uniformidade desses fatores a vegetação pujante da selva e a notável rede de rios e lagos além da forte nebulosidade durante 0 ano. Com estas condições, a mâioria dos correlacionamento não foi significativa, provavelmente porque os fatores meteorológicos não atingem extremos acentuados, mantendo-se dentro de um nível ótimo para atividade de Tabanidae (eclosão, atividade de vôo e oviposição). O único correlacionamento verificado foi o da ocorrência sazonal de $P$. cajennensis com a precipitação, deixando esta espécies de ocorrer no início da estação chuvosa, apresentando maior atividade de vôo na estação seca e sendo caracterizada como univoltina. Provavelmente, a atividade desses insetos seja controlada por fatores intrínsecos e são pouco influenciados por condições meteorológicas não extremas, tais como, temperatura e vento.

A técnica de determinar a idade fisiológica das fêmeas atraídas por isca animal, tem a desvantagem de estabelecer somente o número de ciclos completados quando a fêmea chega para obter sangue. Observamos alguns indivíduos de $T$. importunus realizarem três ciclos e chegaram para iniciar o quarto, podendo este ser completado, mas o inseto não sobrevive para iniciar o que seria seu quinto ciclo gonotrófico. Desse modo ficam registrados três ciclos quando, na realidade, podem ocorrer quatro.

A dissecação de um grande número de fêmeas forneceu um aspecto da idade da população e suas mudanças com o tempo. A baixa oniparidade registrada do início ao fim do estudo (em torno de $40 \%$ ) pode ser devida: a) às dificuldades envolvidas em encontrar um hospedeiro, face à pequena densidade de mamíferos na área, b) a dificuidades de obter um repasto sangüineo completo, provavelmente resultante da reação do cavalo à dor provocada pela picada, c) a um contínuo influxo de fêmeas nulíparas na população ou, d) à sobrevivência baixa entre as classes.

Segundo Fairchild (1942), a maioria dos Tabanidae, tanto em regiōes temperadas quanto em tropicais, apresenta um ciclo univoltino, com uma estação de vôo que pode ser muito curta. O mesmo autor mencionou a possibilidade de $T$. importunus apresentar duas estações reprodutoras num ciclo anual ou dois ciclos durante $o$ ano. Nossos resultados mostraram a ocorrência contínua para as três populações do gênero Tabanus, durante todo tempo de coleta. Isto vem demonstrar que estas es- 
pécies apresentam mais de um ciclo ou mesmo são univoltinas, com estações reproduto. ras não definidas ou com tempo de vida ıarval variável. Essas condições levam à emergência de adultos durante todo o ano, emergência esta que foi verificada através da predominância de fêmeas nulíparas nas dissecações, e sendo esta a condição mais óbvia para manter baixa a oniparidade sazonal, juntamente com o baixo índice de sobrevivência registrado.

Os resultados de estádio de desenvolvimento do folículo, quando as fêmeas chegaram para obter o repasto sangüineo, foram semeIhantes aos encontrados por Duke et al. (1956), Anderson (1971), Thomas (1973), Magnarelli \& Pechuman (1975) e Magnarelli (1976), encontrando-se em estádio I-II ou II de Christophers. Dessa maneira, ficou confirmada a diapausa ovariana entre estes estádios, o que é característico das espécies anautógenas. A deposição de vitelo, antes do primeiro repasto sangüineo, demonstra que há suficiente reserva trazida da fase larval ou, então uma provável alimentação de néctar logo após a eciosão (Oldroyd, 1973), que possibilita a deposição de certa quantidade de vitelo no oócito. Para as fêmeas uníparas ou biparas, o repasto sangüineo completo é o responsável por tal deposição de vitelo. Esses resultados comprovam e que Thomas (1973) disse: "a deposição de vitelo começa antes ou imediatamente após a oviposição". Estádios N, III, IV e V dificilmente são encontrados nas fêmeas que chegam para obtenção de sangue. Page (1972) registrou estádios bem avançados de deposição de vitelo em quatro espécies de tabânidas colombianas, procurando obter sangue numa vaca. Isto sugere que tais espécies obtiveram repasto incompleto ou então necessitam de mais de uma refeição para o desenvolvimento total dos ovos. Durante nossas dissecaçōes, fcram registradas apenas quatro fêmeas de $T$. dorsiger var. dorsovittatus $(0,33 \%)$ e duas de $T$. importunus $(1,0 \%)$ com estádios de desenvolvimento entre III e V. Com este baixo número, ficou comprovado que estas espécies não necessitam de mais de um repasto completo para desenvolver um lote de ovos, mostrando assim concordância gonotrófica, em que, a cada ob- tenção de sangue, há o amadurecimento de um lote de ovos.

Quanto à sobrevivência de insetos na natureza, esta pode ser avaliada diretamente através da técnica de marca e recaptura ou indiretamente através da idade da população (Gillies, 1974). A primeira é capaz de fornecer uma estimativa mais real de sobrevivência, mas sua utilidade é freqüentemente limitada pelo baixo número recapturado. Desta sorte, utilizamos a segunda que dá uma estimativa mais precisa de sobrevivência. É importante notar que a segunda técnica é ainda mais precisa quando aplicada a insetos que apresentam concordância gonotrófica. Apesar do baixo índice de sobrevivência registrado para as espécies estudadas, o potencial como vetoras de agentes patogênicos não pode deixar de receber a devida atenção, pois a população persiste com certo indice de oniparidade. T. importunus foi incriminada como transmissora mecânica de Trypanosoma evansi (=equinum) no mal das cadeiras que assolou os cavalos da ilha de Marajó e outras áreas (Lutz, 1908 in Barreto, 1949). Esta mesma espécie foi a que apresentou maior índice de sobrevivência em nossos estudos, sendo a única em que alguns indivíduos realizaram três ciclos gonotróficos. Como esta espécie é anautógena, assim como as outras três, tem maior importância na transmissão de patógenos, pois para a primeira oviposição são obrigadas a procurar um hospedeiro, podendo realizar transmissões mecânicas desde o início do primeiro ciclo. Uma fêmea, nulípara que ao alimentar-se, utiliza vários hospedeiros (em virtude do repasto interrompido) pode ter igual ou maior importância como vetoras mecânicas do que uma unípara que tenha conseguido sangue de um único hospedeiro para maturar seus ovos.

A pequena quantidade de legenerações sugere que as fêmeas adquirem suficientes nutrientes para amadurecer o número máximo de folículos ou, quando isto não ocorre, amadurece a quantidade proporcional à quantidade de sangue obtida, conforme evidência por nós verificadas. Magnarelli (1976) nãc encontrou nenhuma evidência indicando maturação de alguns folículos, enquanto outros perma- 
neciam em estado de descanço, porém, nossos resultados não coincidiram com estes; encontramos e registramos tais folículos em descanço, enquanto ocorria deposição de vitelo nos outros (Fig. 17). Mesmo durante as observações dos pedicelos, por vezes, encontrávamos alguns com dilatações (indicando a prévia maturação do folículo) e outros sem as mesmas (permaneceram em descanço). O princípio do "tudo ou nada" aplicado por Duke et al. (1956) não pode ser aplicado às espécies aqui estudadas, pois, conforme nossos encontros, não há evidências de um volume de sangue, acima do qual ocorre o desenvolvimento dos ovos e abaixo do qual nenhum desenvolvimento virtual ocorre.

A duração mínima provável do ciclo gonotrófico - seis dias - encontra-se um pouco abaixo dos resultados encontrados para outras espécies, de regiöes temperadas. MacClain et al. (1975) registra 6,6 dias para Tabanus quinquevittatus e 8,0 dias para Hybomitra lasiophthalma. A temperatura provavelmente é a causa dessas diferenças, pois as espécies tropicais estão sujeitas a uma temperatura mais elevada e conseqüentemente amadurecem seus folículos mais rapidamente

\section{Agradecimentos}

Os autores agradecem à Universidade do Amazonas, pela utilização do Campus Universitário e empréstimo dos animais, ao Dr. G B. Fairchild da Universidade da Flórida EUA pela identificação dos Tabanidae, aos técnicos Alberto Nápoles e Altamiro Soares pelo auxílio nas coletas de campo e ao desenhista Jorge Dácio pela feitura dos gráficos.

\section{SUMMARY}

The four populations studied, Tabanus dorsiger var. dorsovittatus, T. d. var. modestus, T. importunus and Phaeotabanus cajennensis, presented low seasonal parity. The duration of the gonotrophic cycle was uniform, attaining Christopher's stage V in 120 hours after a complete blood meal. The majority of captured females that arrived to feed on an animal had stage II follicles. Only P. cajennensis was not registered throug- hout the year, not occuring from December to the deginning of February, at the start of the rainy season. Flight activity was greates in the afternoon, and differences in activity between nulliparous and parous females was not significant $\left(x^{2}>0,05\right)$

\section{BIBLIOGRAFIA}

ALVERSON, D.R. \& NOBLET, R.

1977 - Activity of female Tabanidae (Diptera) in relation to selected meteorological factors in south Carolina. J. Med. Ent., 14 (2): 197. 200 .

ANDERSON, J.F.

1971 - Antogeny and mating and their relationship to biting in the salt marsh deer-fly Chrysops atlanticus (Dintera: Tabanidae) Ann. Ent. Soc. Am., 64 (6): 1421-1424.

BARRETO, M.P.

1949 - Importância médica e econômica dos ta bânidas. Rev. Clin. S. Paulo. 25: 59-68.

BERTRAM, D.S.

1962 - The ovary and ovarioles of mosquitos. In: Age grouping method in Diptera of medical importance. T. S. Detinova. Geneva, WHO. p. $195-210$.

Bracken, G.K.; HaNec, WM, \& ThorstenNSON, A.J.

1962 - The orientation of horse flies and deer flies (Diptera: Tabanidae). II - the role of some visual factors in the attractiveness of decoy silhouetes. Can. J. Zool., 40: 685-695.

BURNeTt, A.M. \& HAYES, K.L.

1974 - Some influences of meteorological factors on flight activity of female horseflies (Diptera: Tabanidae). Env. Ent., 3: 515-521.

Charlwood, J.D.; RAFAel, J.A. \& Wilkes, T.J.

s.d. - Métodos de determinar a idade tisiológica em Diptera de importância médica. Uma revisäo com especial referência aos vetores de doenças na América do Sul. Acta Amazonica (entregue para publicação).

DALE, W.E. \& AXTELL, R.C.

1975 - Flight of the salt marsh Tabanidae (Diptera). Tabanus nigrovittatus, Chrysops atlanticus and $\mathbf{C}$. fuliginosus: correlation with temperature, light, moisture and wind velocity J. Med. Ent., 12 (5): 551-557

DeFollart, G.R.; RAO, M.R. \& MORRIS, C.D.

1967 - Seasonal sucession of bloodsucking Diptera in Wisconsin during 1965. J. Med. Ent., 4 (3): $363-373$.

DETINOVA, T.S.

1962 - Age-grouping methods in Diptera of medical importance. Geneva, W.H.O., 216 pp. 
DUKE, B.O.L.

1956 - The relationship between the size of the blood meal taken in by Chrysops silacea, the development of the fly's ovaries, and the development of the microfilariae of Loa loa take in with the blood meal. Ann. Trop. Med. Parasitol., 50: 283-290.

DUKe, B.O.L.; CREWE, W. \& BeEsLey, W.N.

1960 - Studies on biting habits of Chrysops VII The biting cycle of nulliparous and parous C. silacea and C. dimidiata (bomb form) Ann. Trop. Med. Parasitol., 54: 147-155.

ENGELMANN, F

1970 - The physiology of insect reproduction. New York, Pergamon Press, 307 pp.

FAIRCHILD, G.B,

1942 - The seasonal distribution of some Tabani dae (Diptera) in Panamá. Ann. Ent. Soc Am., 35: 85-91.

FORATTINI, O.P.

1962 - Entomologia Médica. 1. vol., São Paulo, Faculdade de Higiene e Saúde Pública. $662 \mathrm{pp}$.

GILLIES, M.T.

1974 - Methods for assessing the density and survival of blood-sucking Diptera. Ann. Rev. Ent., 19: 345-351.

GOMES, F.P.

1977 - Curso de estatistica experimental. 7." ed. Piracicaba, Livraria Nobel, $430 \mathrm{pp}$.

HockING, B.

1971 - Blood-sucking behaviour of terrestrial arthropods. Ann. Rev. Ent., 16: 1-26

I.B.G.E.

1977 - Geografia do Brasil - Regiáo Norte. Rio de Janeiro, Sergraf, $466 \mathrm{pp}$.

KRINSKY, W.L.

1976 - Animal disease agents transmitted by horse flies and deer flies (Diptera: Tabanidae). J. Med. Ent., 13 (3): 225-275

MacClain, D.S. MatThyse, J.G. \& Kemen, M.J., JR.

1975 - Biological notes on three species of Tabanidae (Diptera) obtained during experiments on transmission of equine infectious anemia of horses. J. Med. Ent., 12 (1): 65-71.

Magnarelli, L.A.

1975 - Ovarian studies of Tabanus quinquevitattus Diptera: Tabanidae). J. Med. Ent., 11 (6): 687-690.

Magnarfeli, L.A \& Pechumann, L.L.

1976 - Physiological age of Tabanidae (Diptera) in eastern New York state, USA. J. Med. Ent., 12 (6): $679-682$
MAGNARELLI, L.A. \& ANDERSON, J.F.

1979 - Oviposition, Fecundity and fertility of salt marsh deer fly, Chrysops fuliginosus (Diptera: Tabanidae). J. Med. Ent., 15 (2): 176-179.

OLDROYD, H.

1973 - Tabanidae. In: Insects and other arthropods of medical importance. London, K.G.V. Smith ed., n. 195-208.

PAGE, W.A.

1972 - Feeding behaviour and trypanosomatid in fections of some tabanids and Culicidae in Colombia. J. Ent. (A)., 47: 1-13.

ROBERTS, R.H.

1966 - Biological studies of Tabanidae 1. Induced oviposition. Mosq. News, 26 (3): 435-438.

1974 - Diurnal activity of Tabanidae based on collection in Malaise traps. Mosq. News, 34 (2): $220-223$.

1977 - A technique for the collection of engorged Tabanidae. Mosq. News, 37 (4): 763-764.

ROCKEL, E.G.

1969 - Antogeny in deer fly, Chrysops fuliginosus (Diptera: Tabanidae). J. Med Ent., 6 (2): 140-142.

THомаs, A.W.

1972 - Physiological age structure of adult tabanid populations (Diptera: Tabanidae) in Alberta, Canada. J. Med. Ent., 9 (4): 295-300.

1973 - Follicle developmental stages in bloodsucking horseflies (Diptera: Tabanidae) in Alberta, Canada. J. Med. Ent., 10 (4): 325328.

Thorpe, K.W. \& Hansens, E.J.

1978 - Diurnal activity of Chrysops atlanticus: some questions concerning sampling techniques. Env. Ent., 7 (6): 871-873.

TOWNES, $\mathrm{H}$

1962 - Design for a Malaise trap. Proc. Ent. Soc. Wash., 64 (4): 253-262.

Troubridge, D.A. \& DAvies, D.M.

1975 - Seasonal changes in physiological age composition of tabanid (Diptera) populations in southern Ontario. J. Med. Ent., 12 (4): 453457.

WILKES, TJ.

1975 - The application of advanced age-grading techniques to mosquitoes. Thesis, Institute of Science and Technology. England. 39 pp.

(Aceito para publicação em 06/05/80)

Idade... 